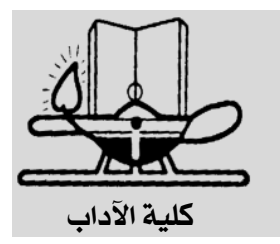

حوليات آداب عين شمس (عدد خاص 1 ( • ( ) http://www.aafu.journals.ekb.eg

(دورية علمية محكمة)

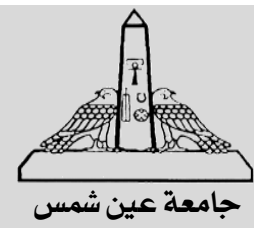

"أدب الأطفال عند خليفة حسين هصطفى "

حنان الصغير أبو القاسم

يُعدُّ أدب الأطفال من الزوايا المنسية في الدراسات الأدبية و النقدية برغم أهميتها،

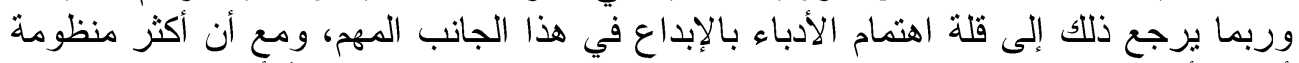

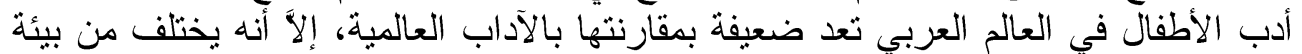

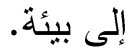

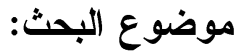

تناولت الدر اسة الدور الريادي للكاتب الليبي خليفة حسين مصطفي في أدب الأطفال - در اسة نقدية في الشكل و المضمون.

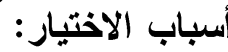

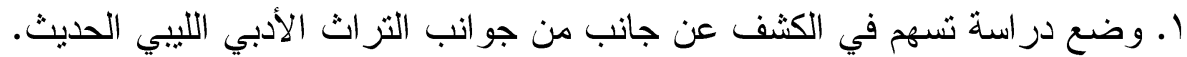

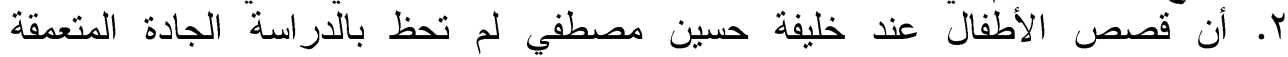

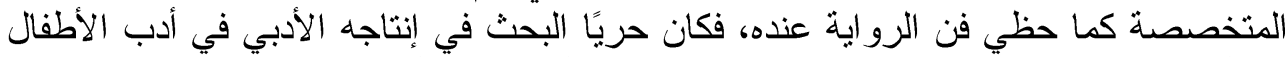
من أجل وضعه في المكان المناسب له بين الفنون الأخرى من أعماله.

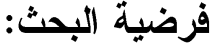

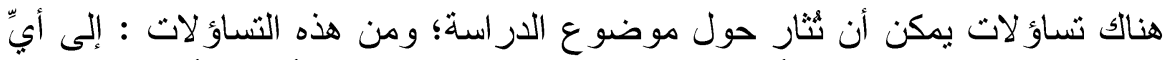

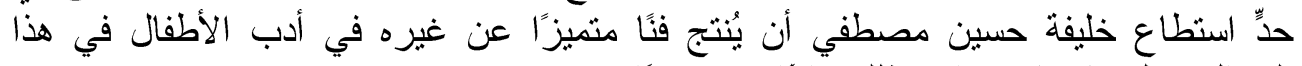

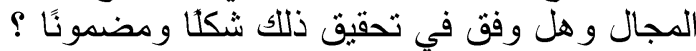

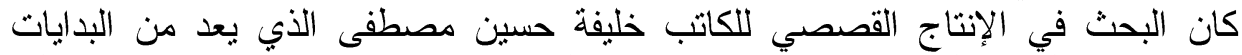

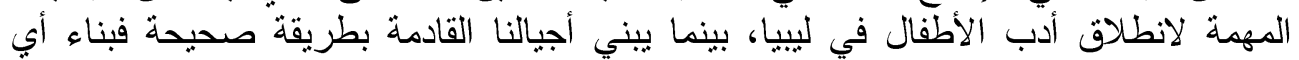

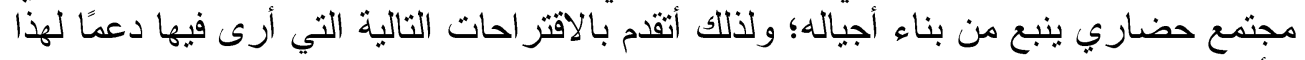

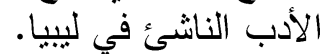
(1) التخطيط الجيد للتعامل مع الثقنية الحديثة بشكل يخدم أدب الأطفال في ظل نو افرها بأبدي كثيرة من الأطفال كالإنترنت مثتا لتقديم أعمال ترتقي بالطفل كعمل مكتبات رقمية خاصة

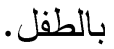
بام) محاولة تذليل الصعوبات التي تواجه كتاب أدب الأطفال في ليبيا النققات المالية منها

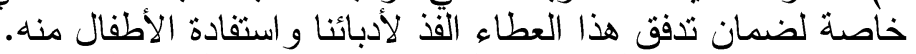

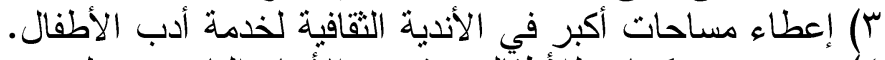

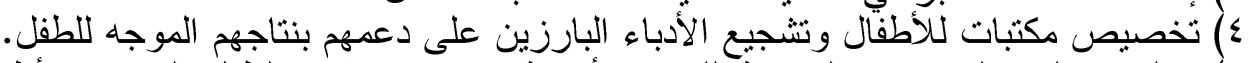

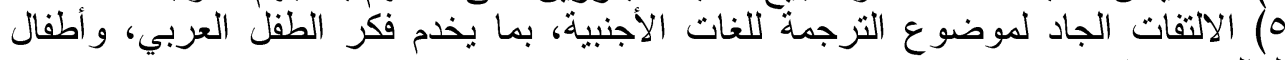

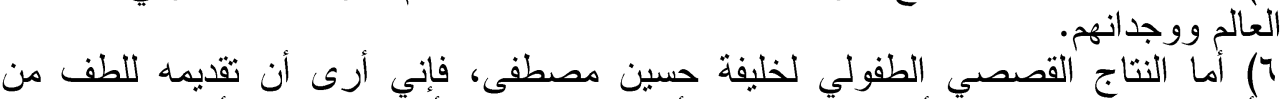

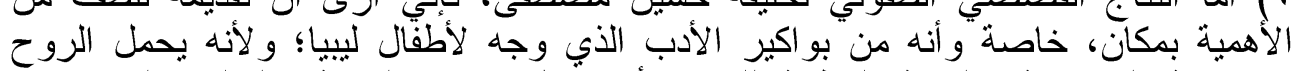

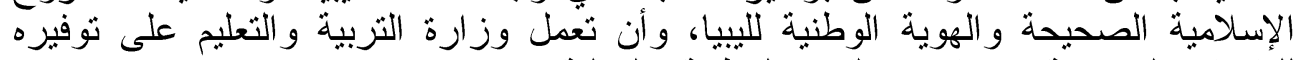
للمكتبات المدرسية، ومعارض وض الكتب الوطنة الوطنية و الدولية.

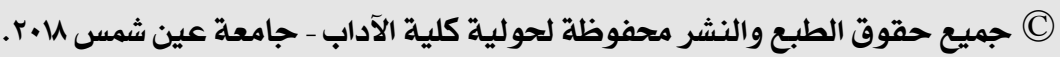




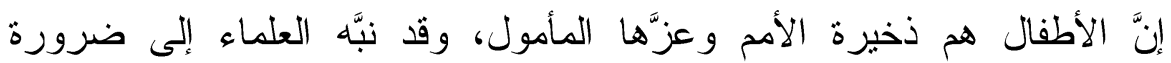

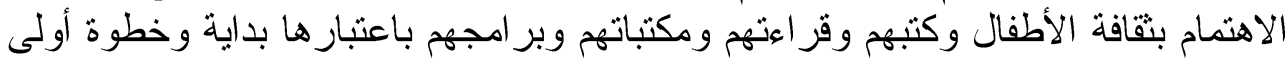
على طريق خلق جيل واع منقف. يُعدُّ أدب الأطفال من الزو الزيا المنسية في الدراسات الأدبية و النقدية برغم أهميتها،

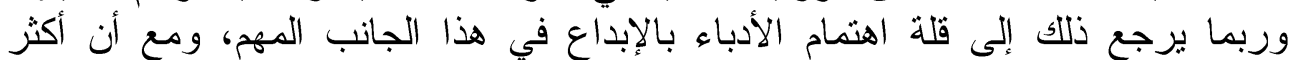

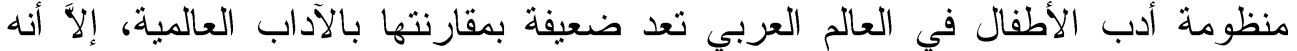

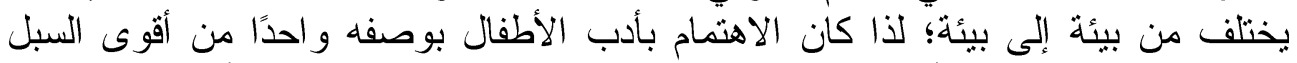

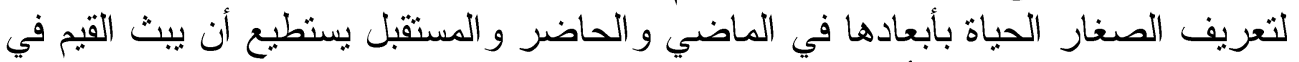

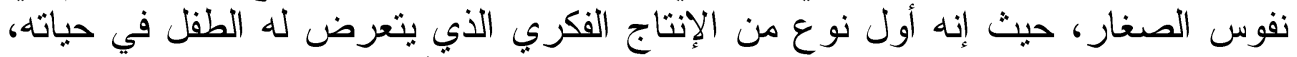

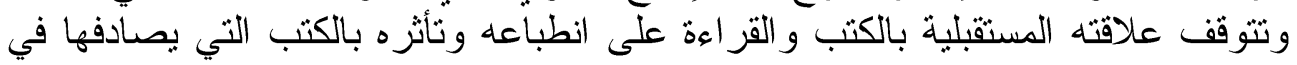

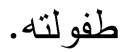

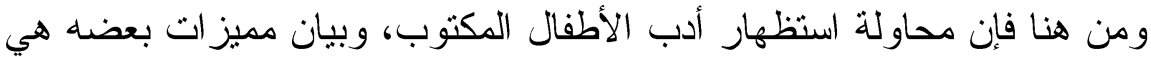

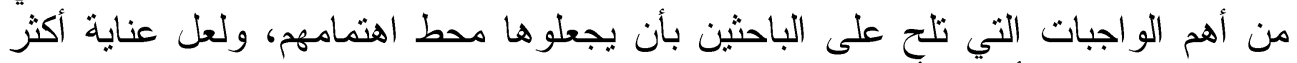

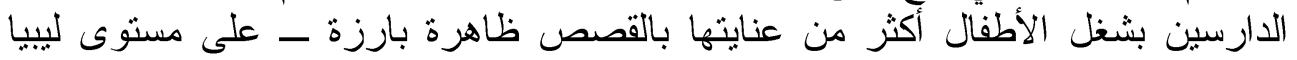

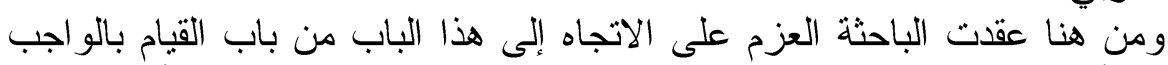
و الوطن العربي.

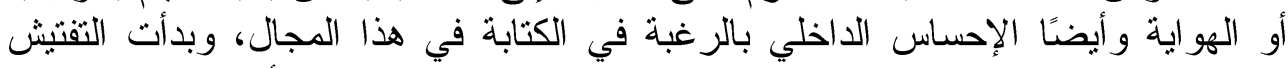

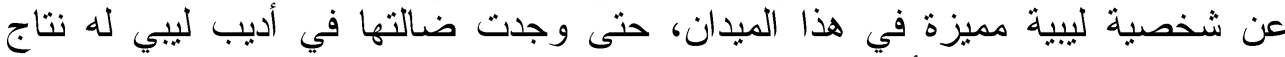

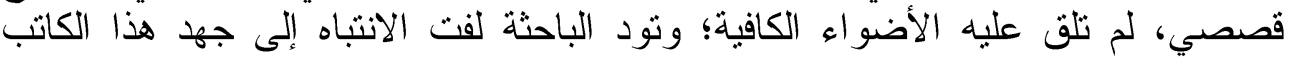
اللبي (خليفة حسين مصطفى). تتاولت الدراسة الدور الريادي للكاتب الليبي خليفة حسين مصطفي في أدب

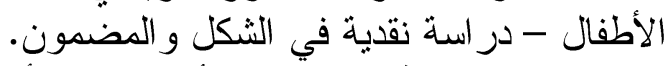

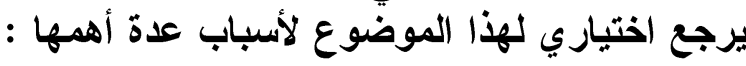

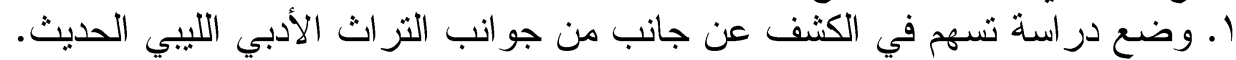

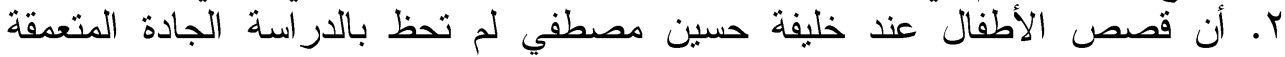

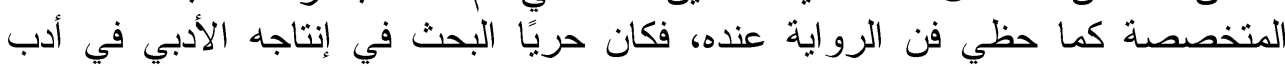

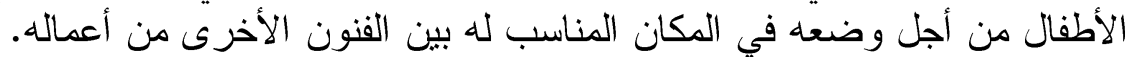

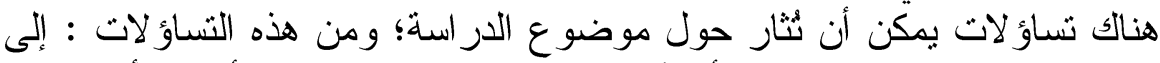

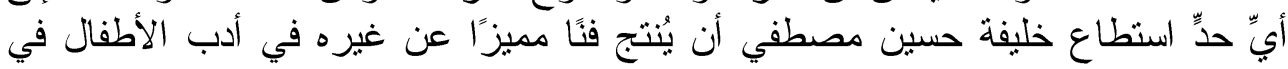

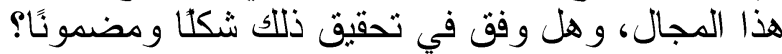




\section{التعريف بأدب الأطفال}

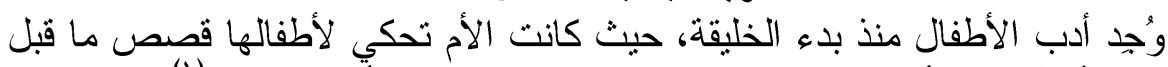

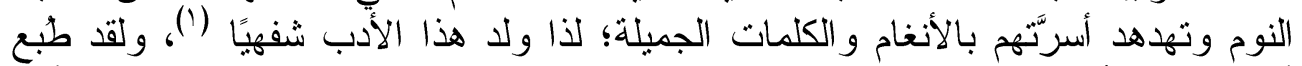

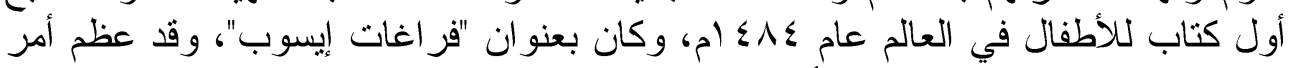

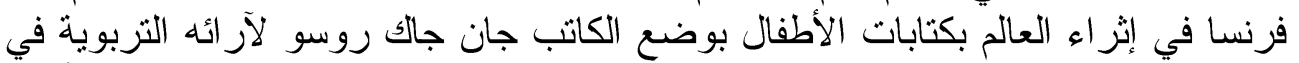

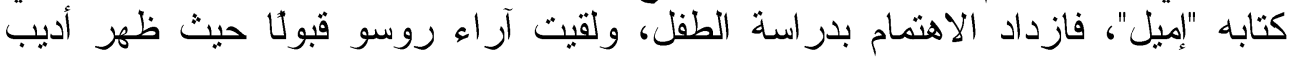

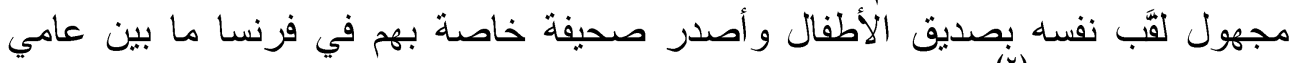

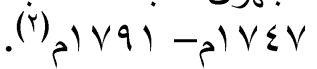

\section{ظهور أدب الأطفال عالميًا}

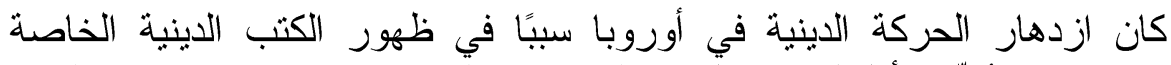

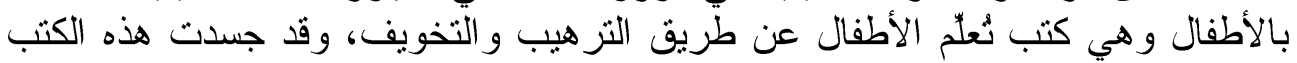

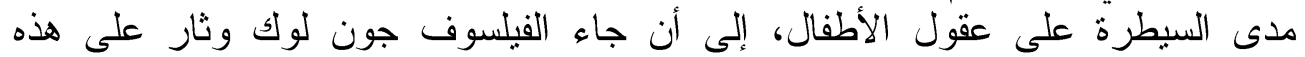

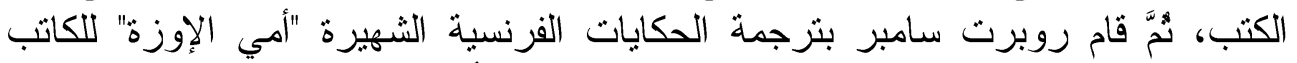

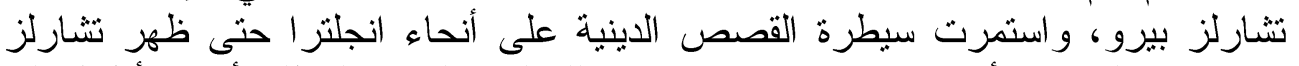

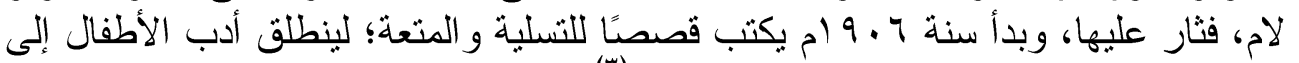

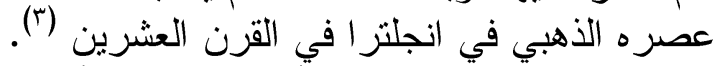

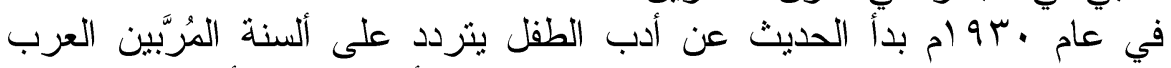

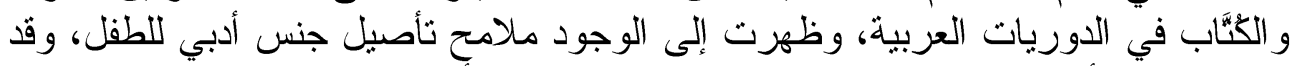

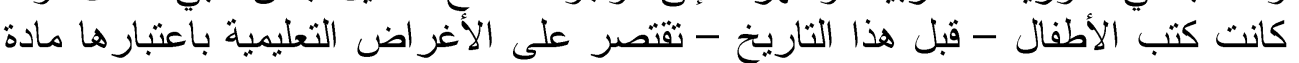

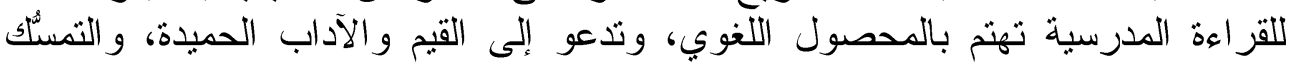

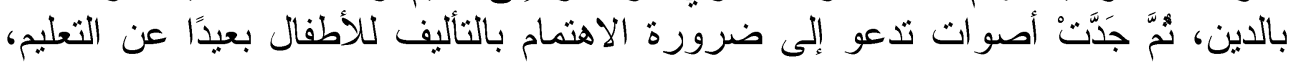

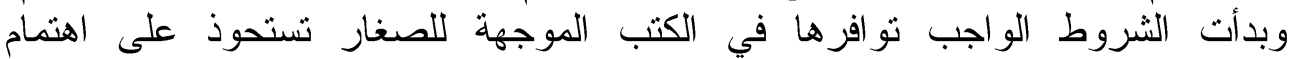

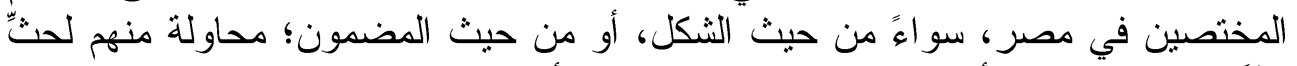

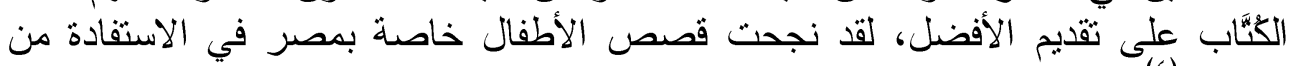
التز الثيناب (£)

كانت بداية انطلاق أدب الأطفال الحقيقية في العالم منذ أواسط القرن التأه التاسع

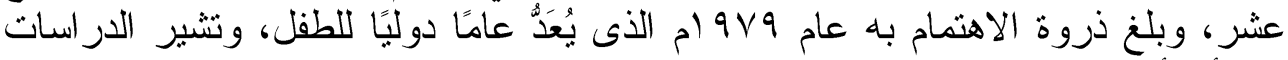

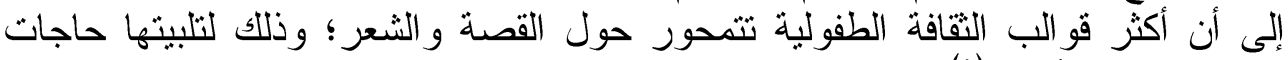
الإطلاع لدى الأطفال (0). أما عن مفهوم أدب الأطفال، فيرى بعض الغََّّب أنه: "خبرة لغوية في شكل فني

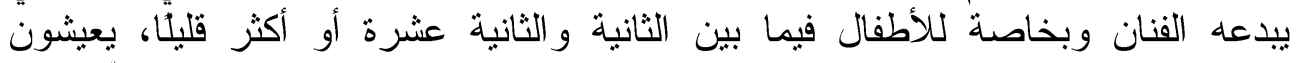

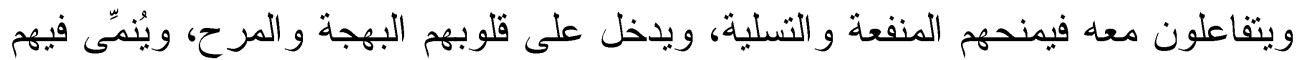

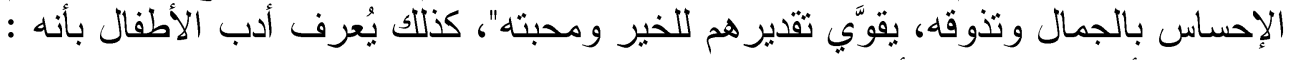

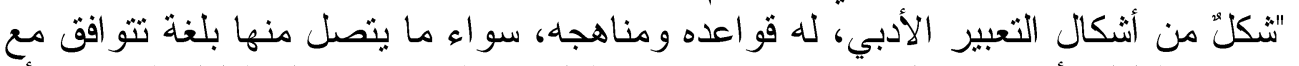

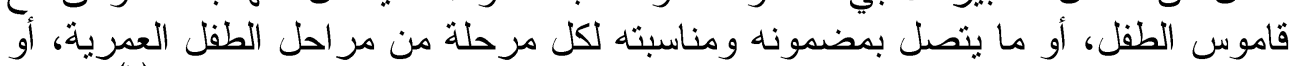

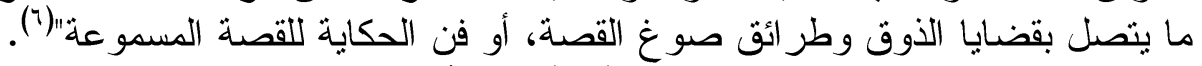

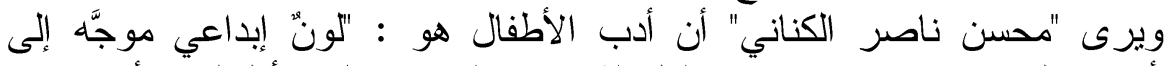

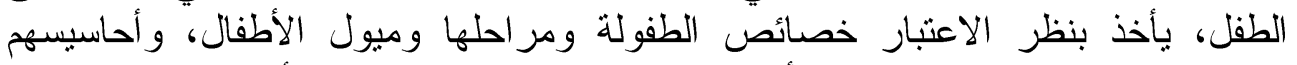
و انفعالاته، وهو جزء من ثقافة الأطفال التي هي - بلا شك - ثقافة أساسية وليست ثقافة ولئة 


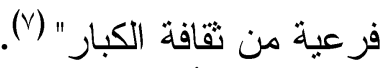

ويُعَدُ أدب الأطفال العربي، وسيلة مهمة جدًا من وسائل الدعوة إلى القيم العربية

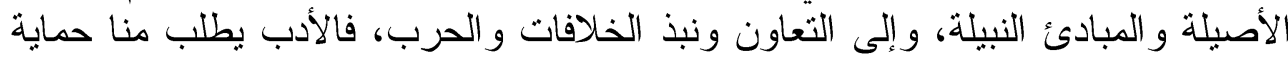

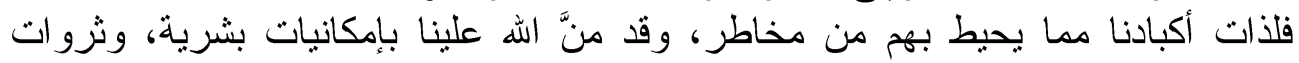

متعددة تغطى احتياجاتنا.

وقد ظهر هذا اللون الإبداعي منأخرًا؛ لأنه يحتاج إلى استقرار سياسي واجتماعي فأني

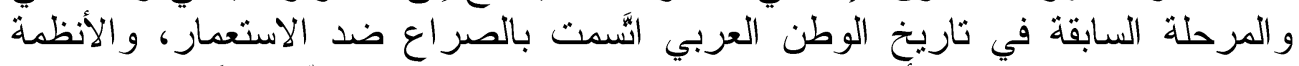

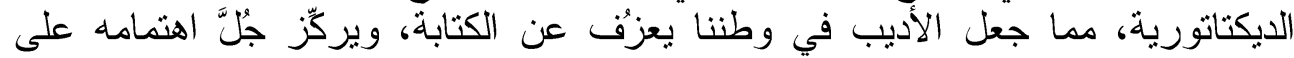

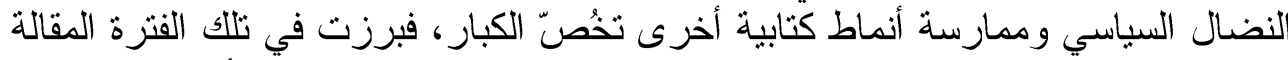

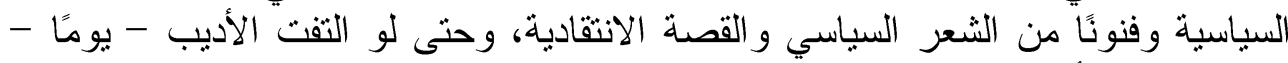

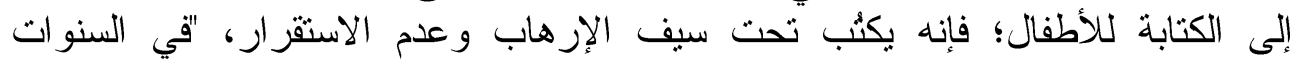

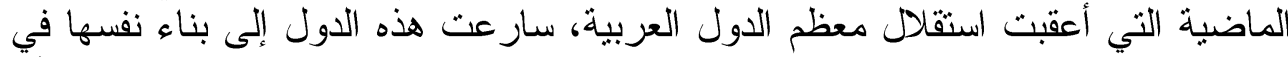

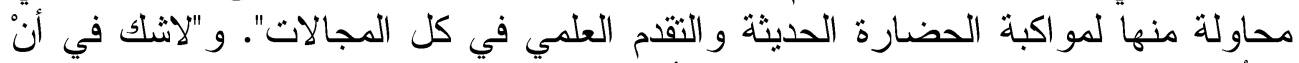

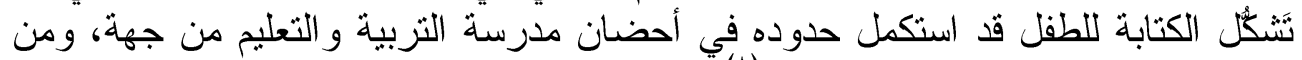

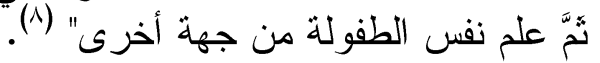

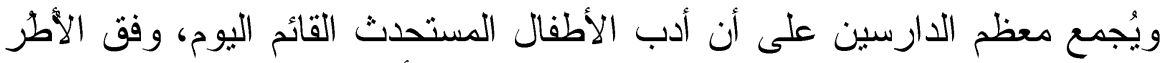

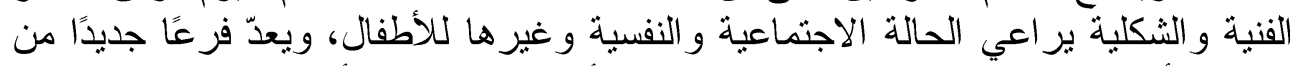

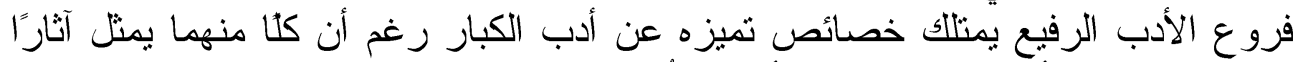

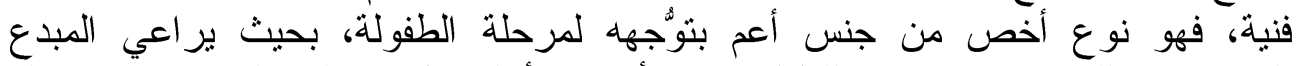

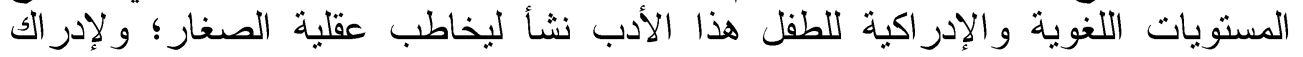

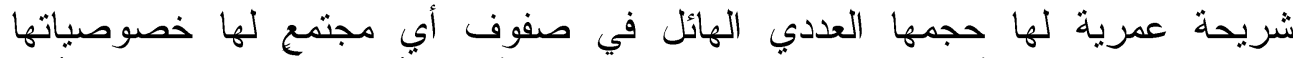

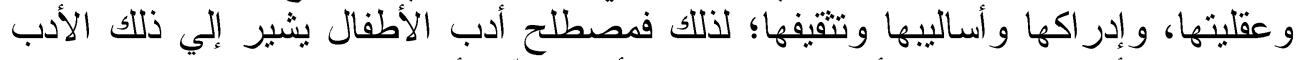

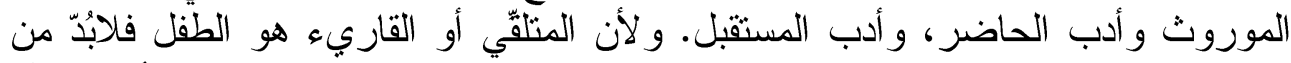

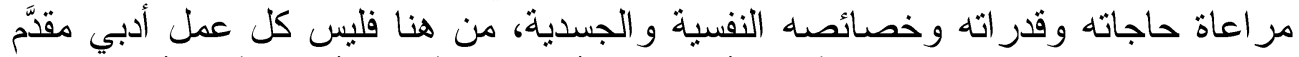

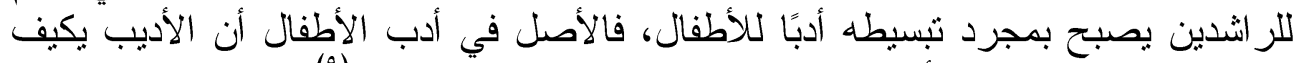

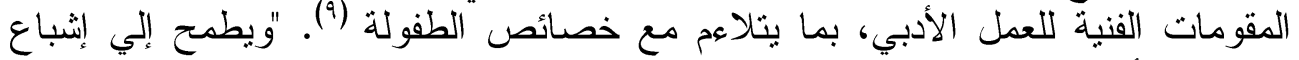

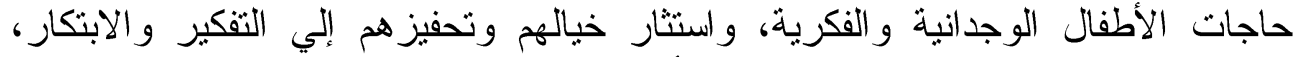

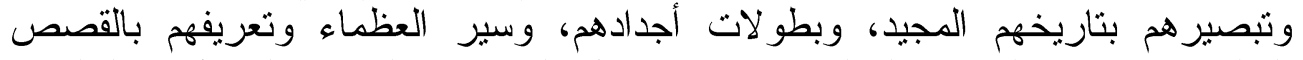
العالمية، وتحقيق المتعة والتسلية مع عدم إغفال المقاصد و الغايات الوعنية ونظية و السلوكية

وفي العشرينيات من القرن العشرين ظهرت أول قصدة لكأطفال بقلم كامل

و التعليمية" (.')

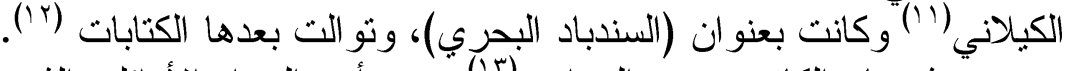

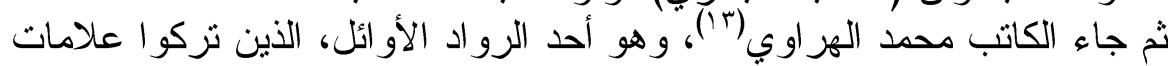

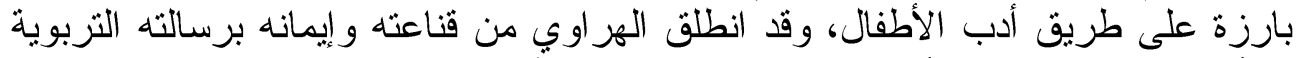

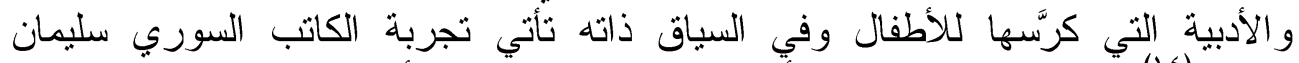

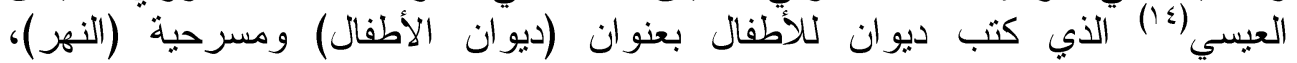

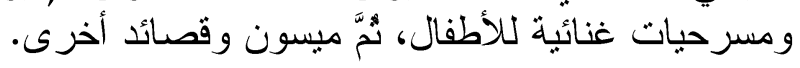




\section{أدب الأطفال في ليبيا}

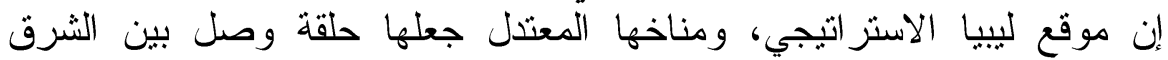

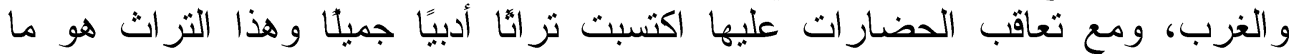

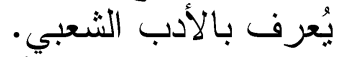

فيقول خليل أحمد خليل: "'لذلك كان الاعتر اف - عالميًا - بتأثير الحكاية الشعبية

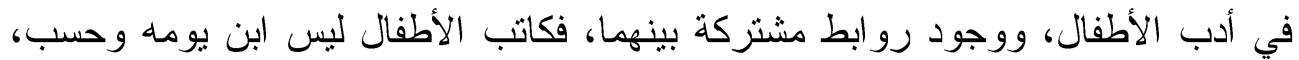

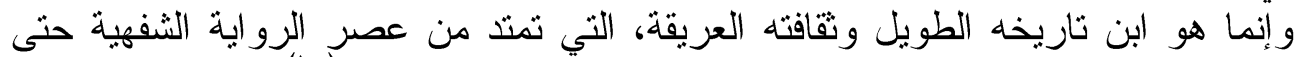

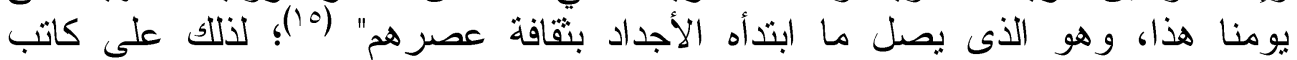

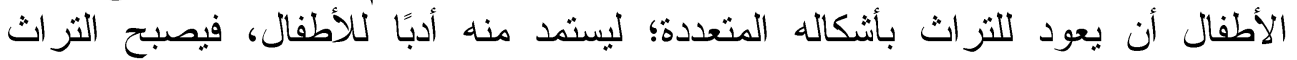

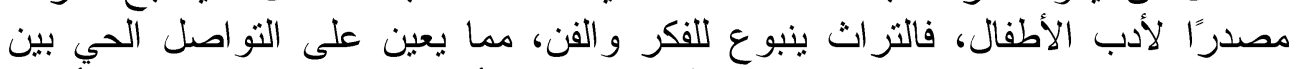

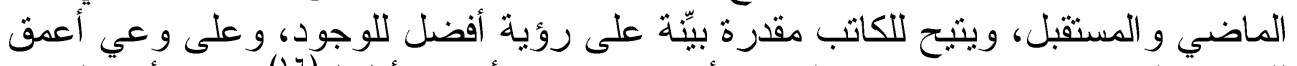

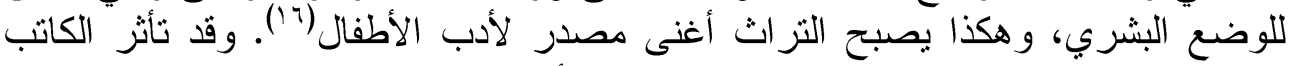

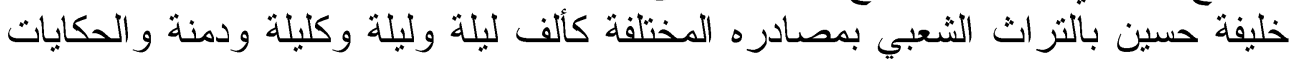

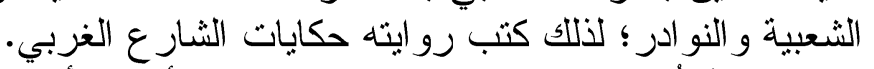

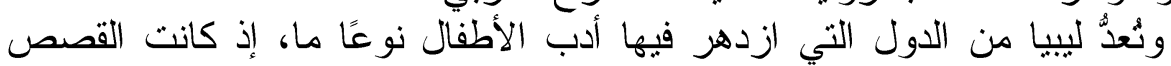

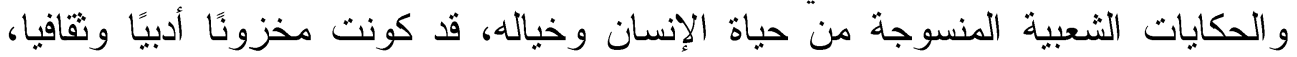

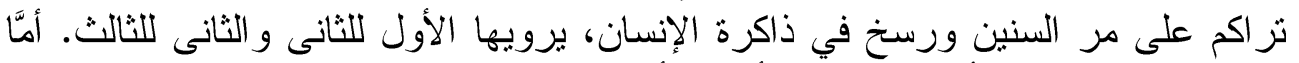

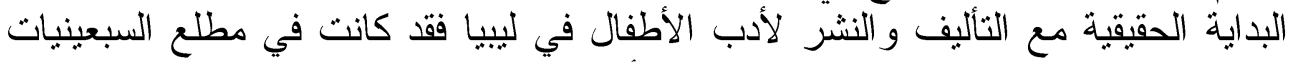

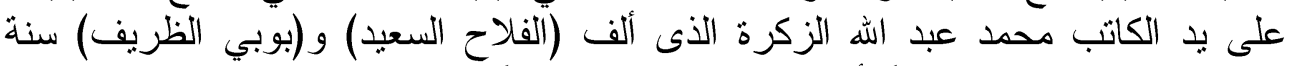

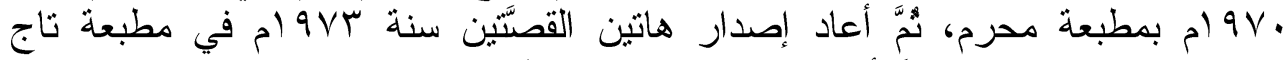

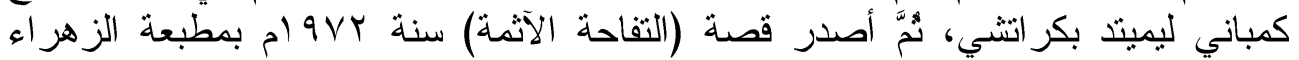

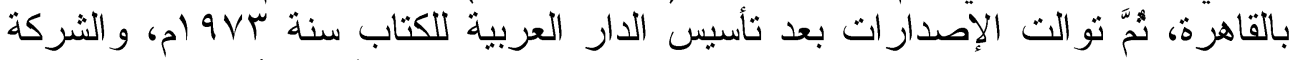

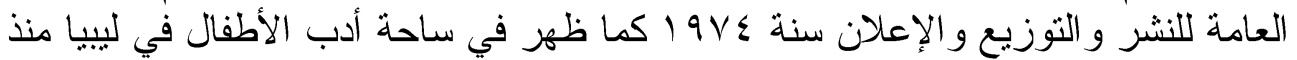

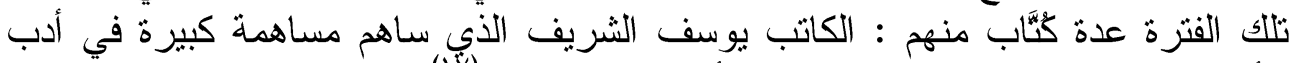

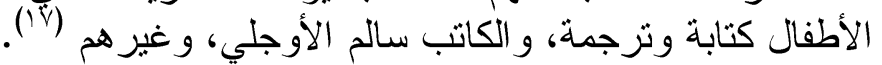

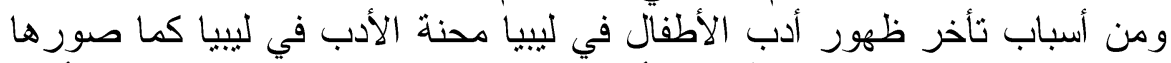

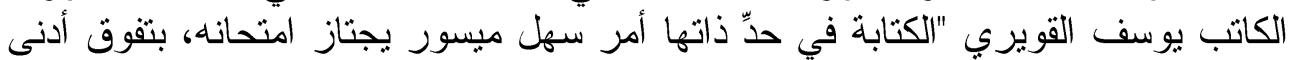

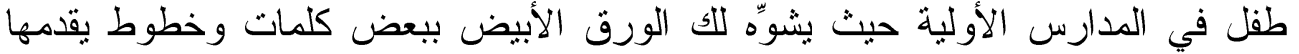

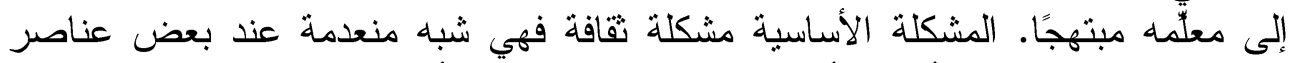

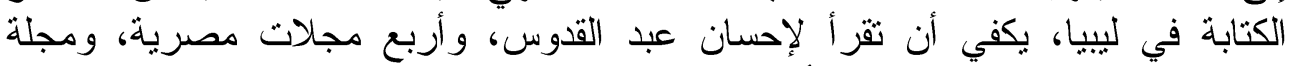

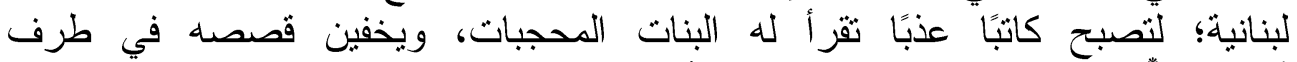

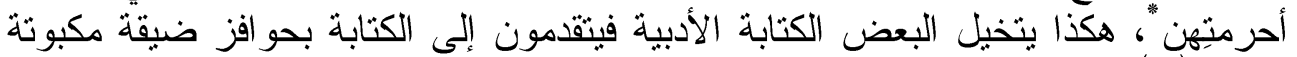
مغلقة" (14) (1).

ولذللك على الأديب أن يكون واسع الاطلاع، كما عليه أن يصوّرّ الو اقع من خلال

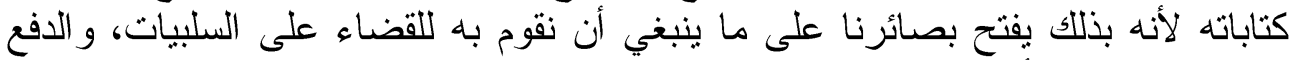

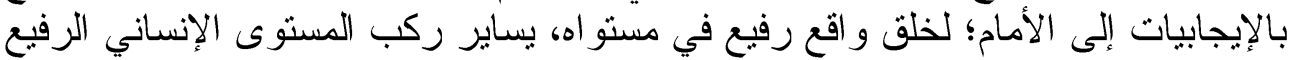

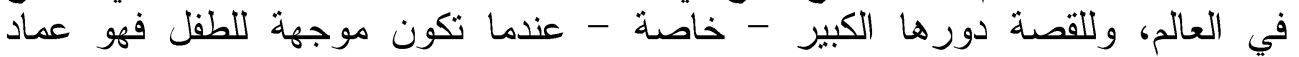

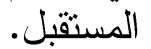


فالقصة كلما كانت ذات بيئة محدودة وزمان ومكان معروفين كانت أكثر إقناعًا

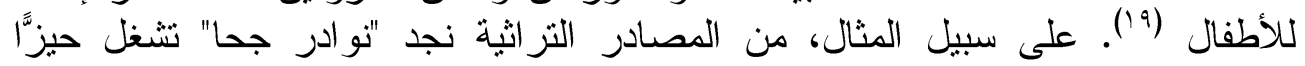

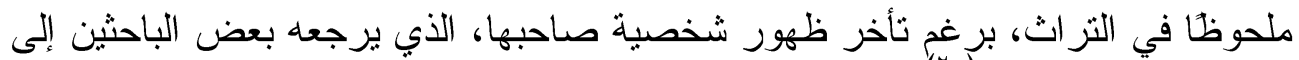

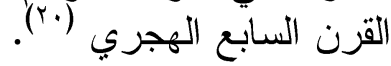
وفي ليبيا كانت الجدَّات تحفظ القصص لترويها للأبناء و الأحفاد مستهلَّة قصنها

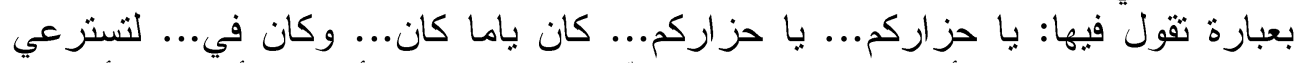

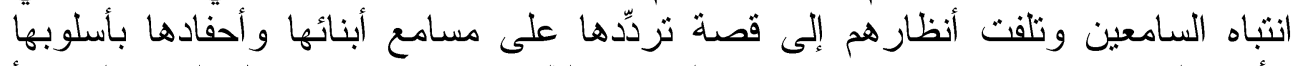

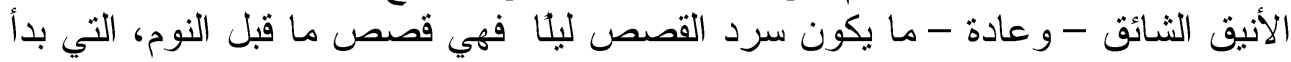

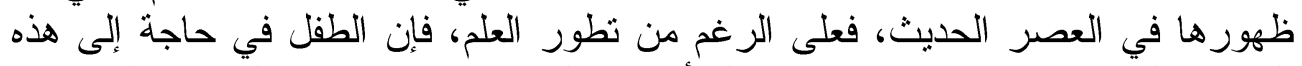

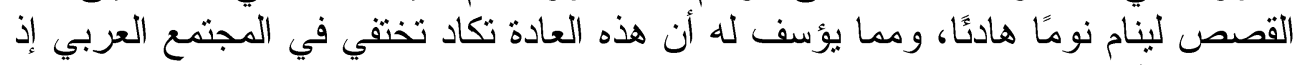
استبدلها الآباء بالتقنيات الحديثة.

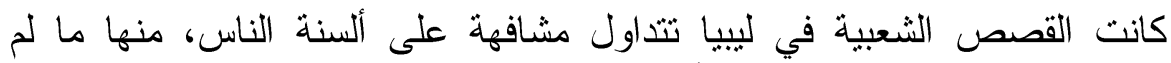

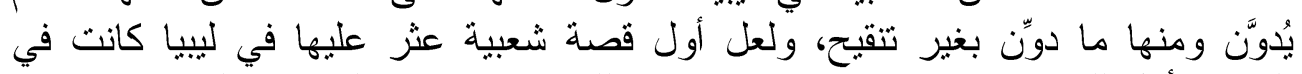

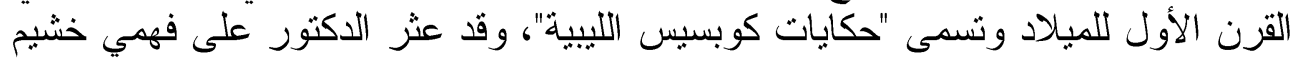

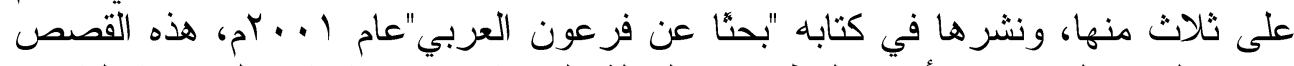

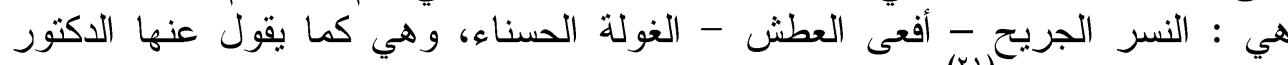

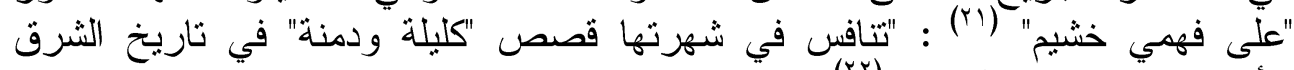

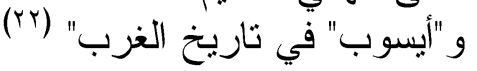

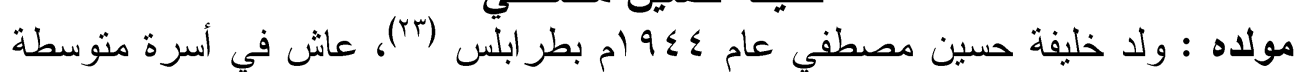

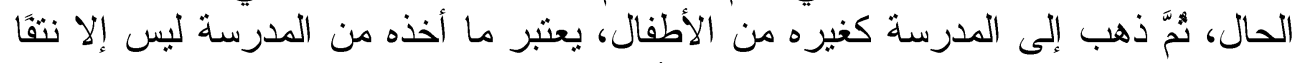

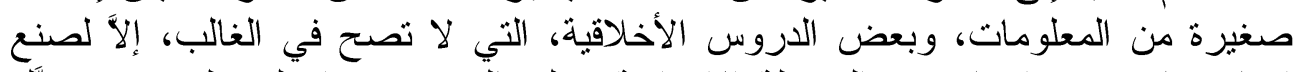

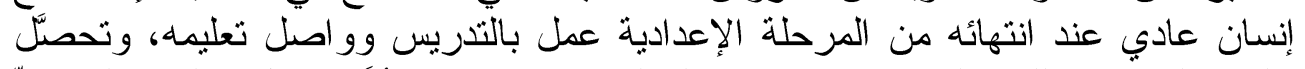

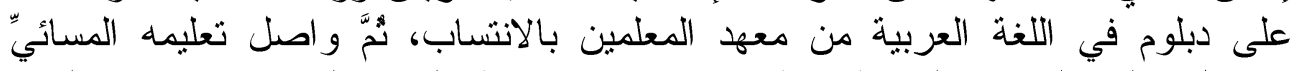

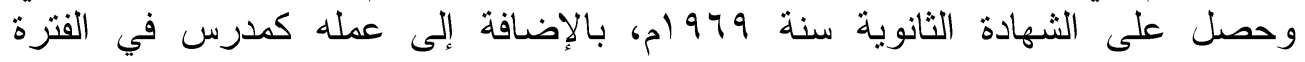

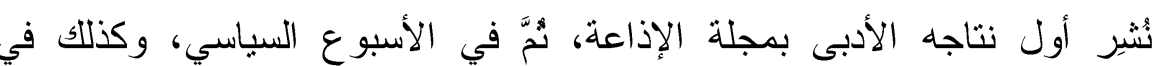
الصباحية. الأسبوع الثقافي و الوحدة، و البلاغ اللبنانية. كما صدرت لله مجموعة من البوغ لإنانة الروايات الأدبية من بينها: المطر وخيول الطين

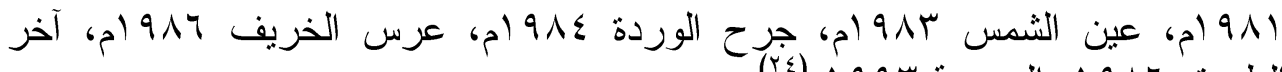

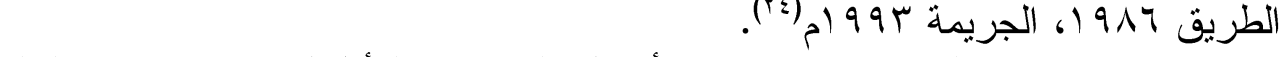
كما صدرت لله مجموعات من الأعمال القصصية للأطفال من بينها : "سلسلة

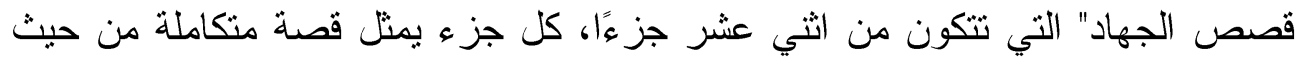

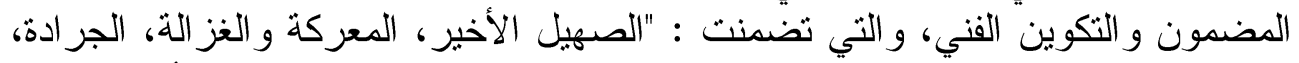

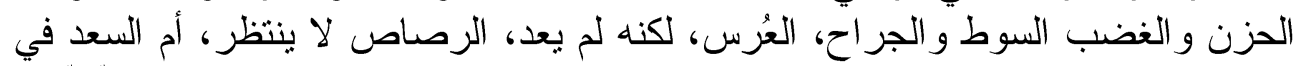

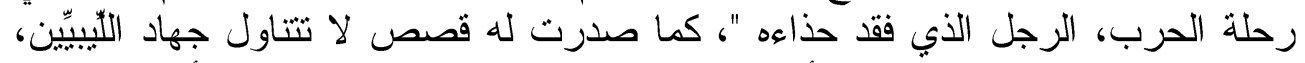

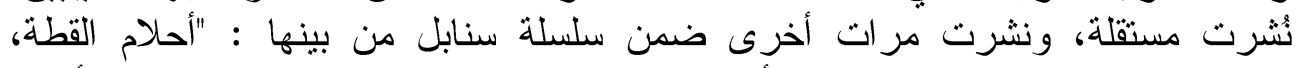

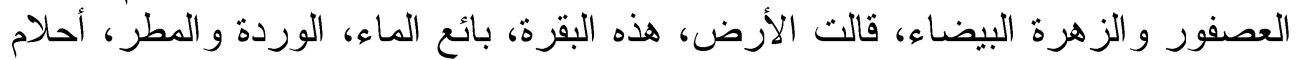

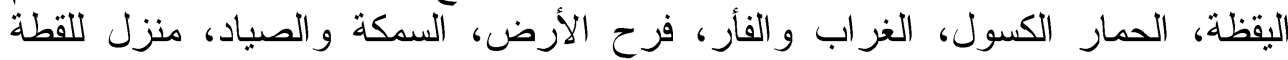




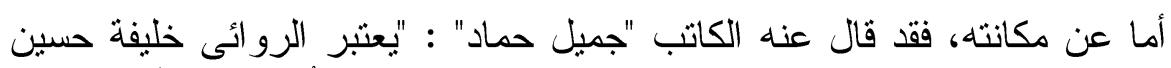

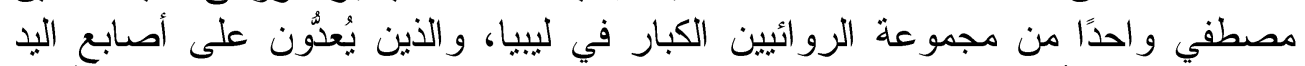

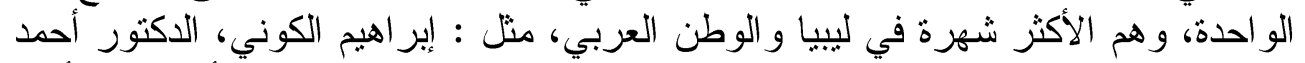

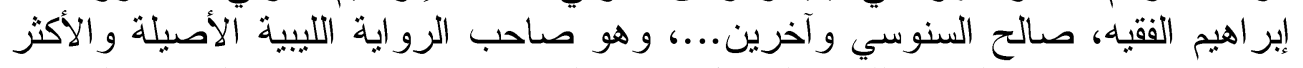

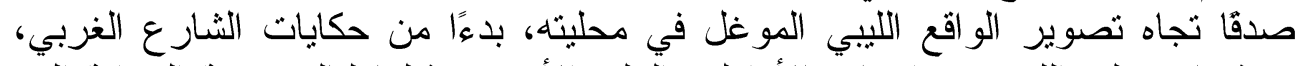

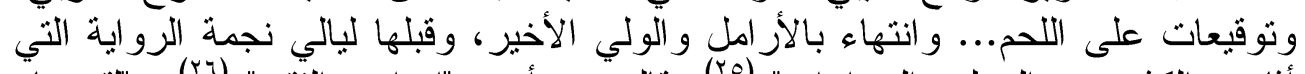

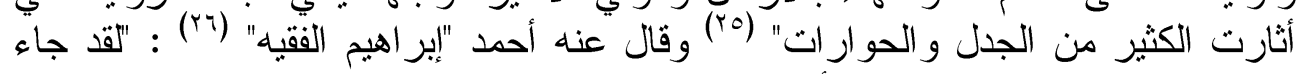

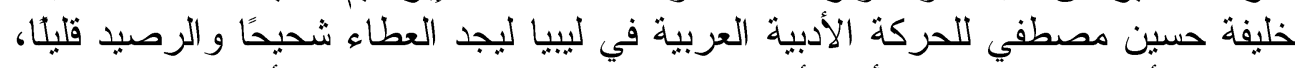

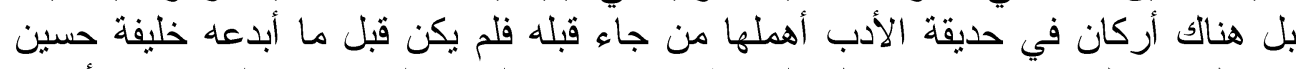

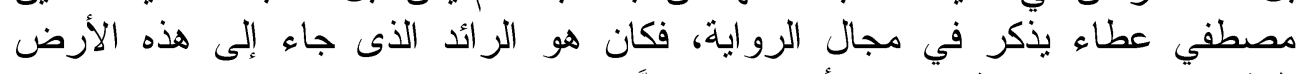

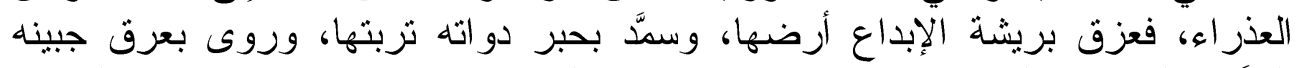

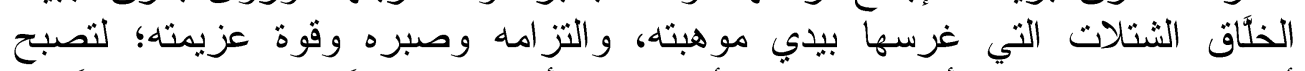

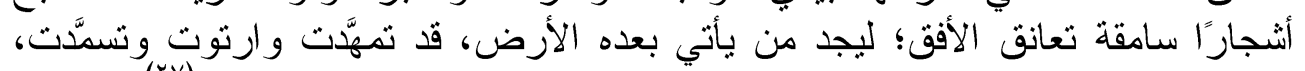

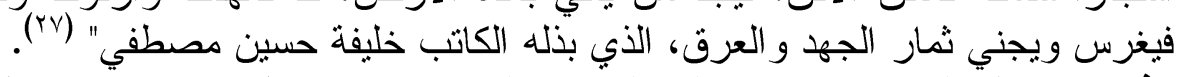

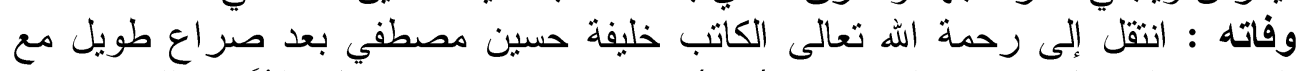

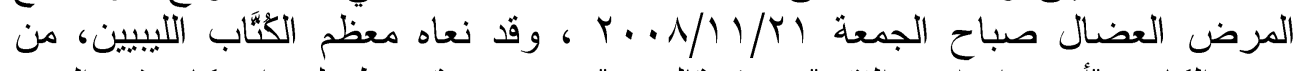

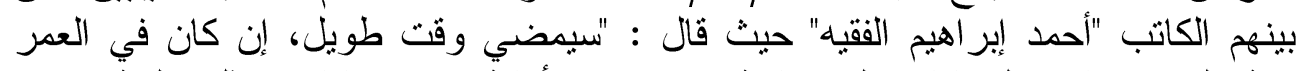

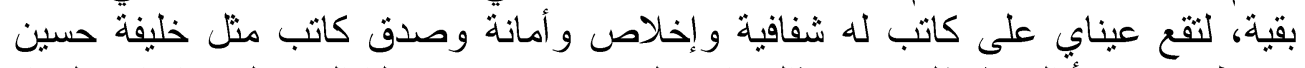

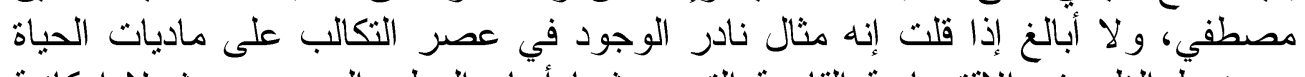

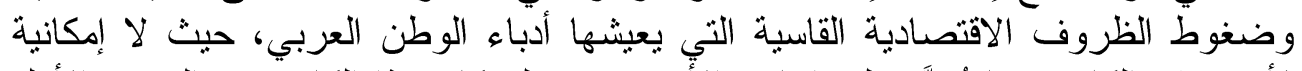

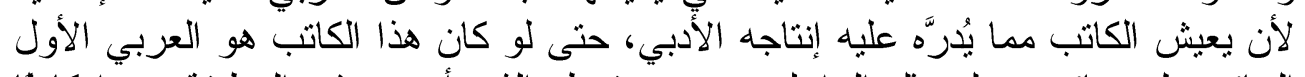

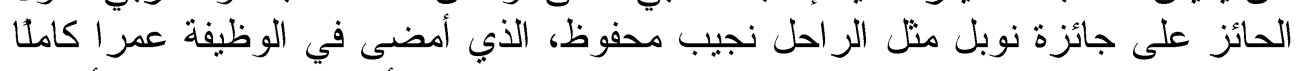

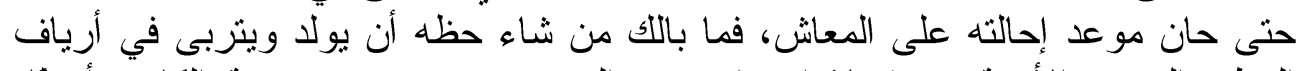

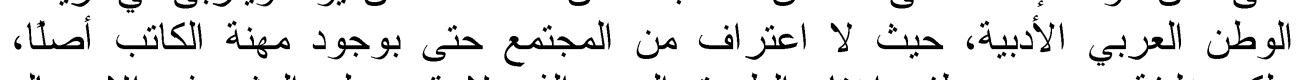

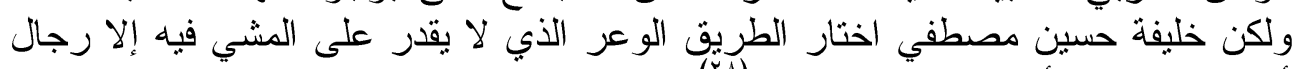

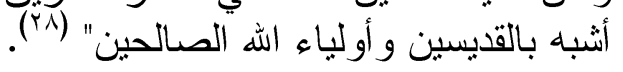




\section{الأدب الطفولي عند الكاتب دراسة موضوعية القضايا التاريخية دانبة}

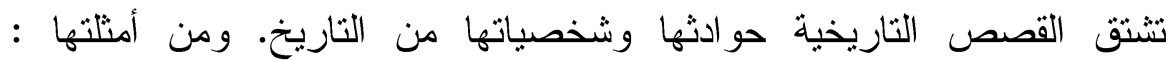

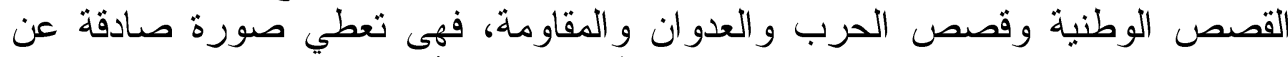
حقبة من الزمن وتعتبر القصص التصاريخية من أنجح كتب الأطفال.

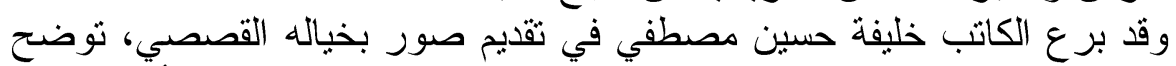

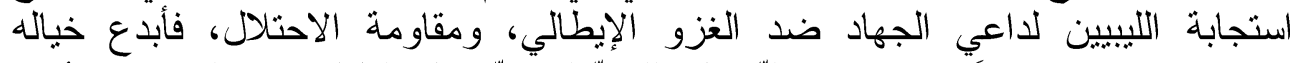

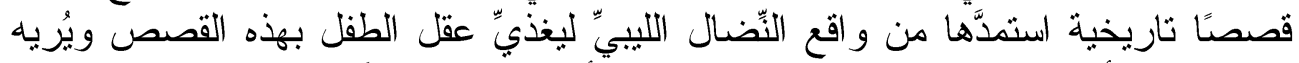

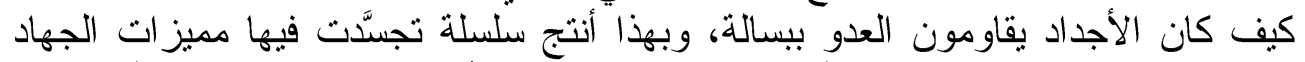

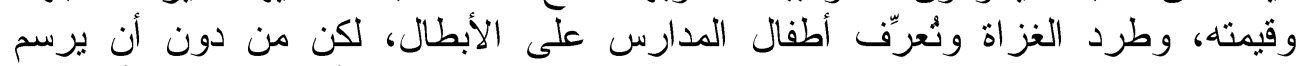

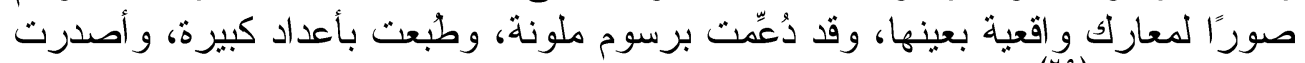

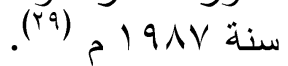

\section{قصة "الصهيل الأخير": - ماكية}

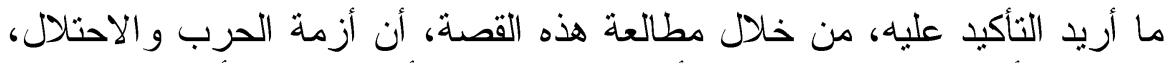

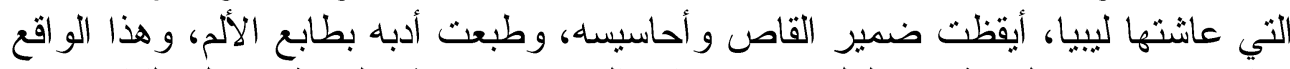

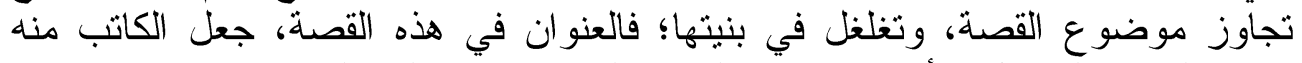

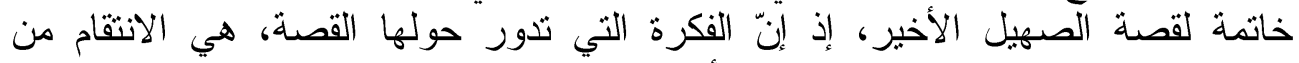

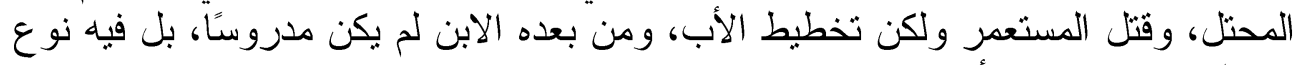

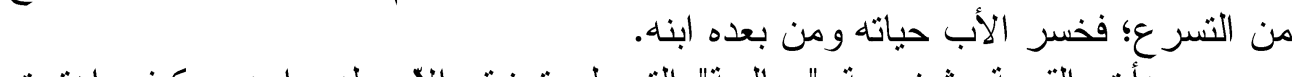

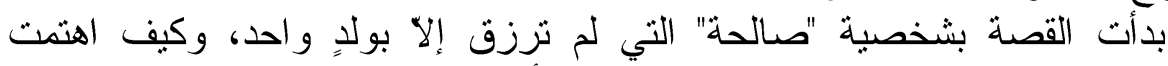

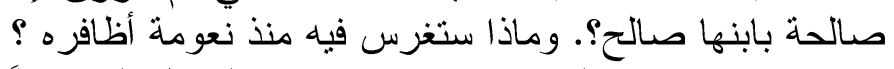

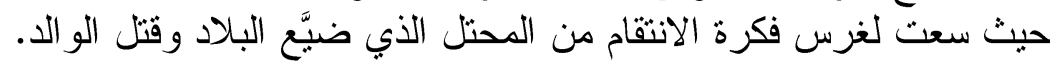

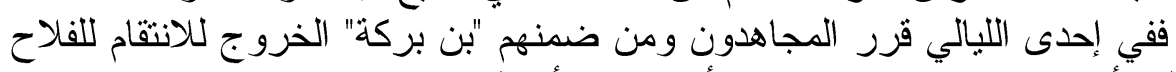

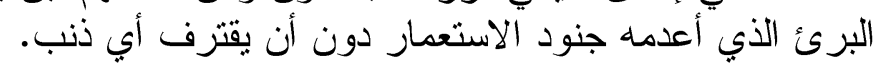

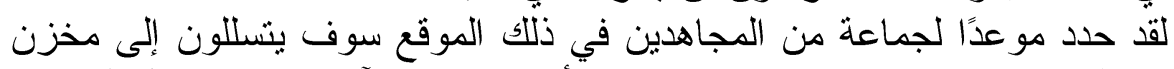

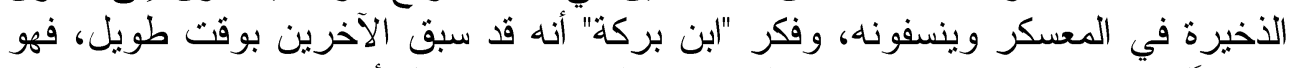

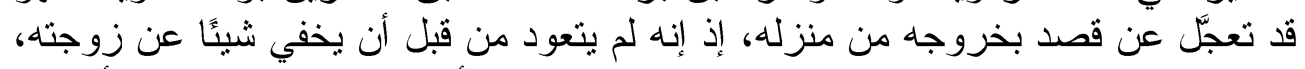

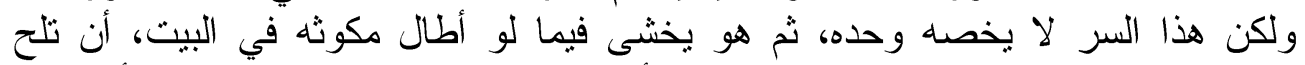

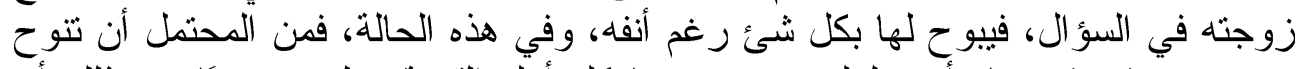

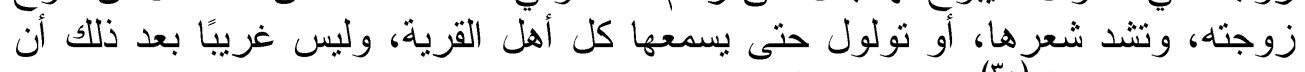

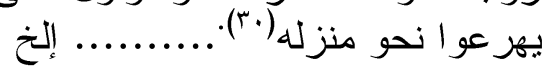

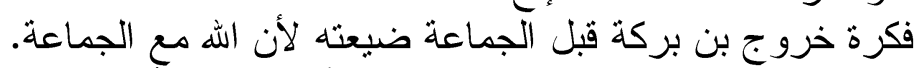

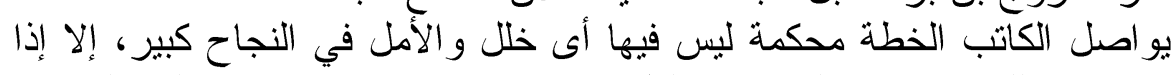

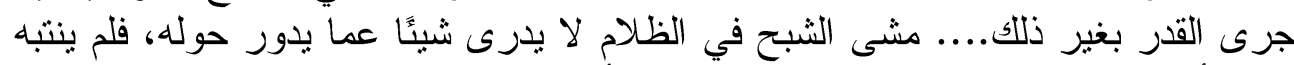

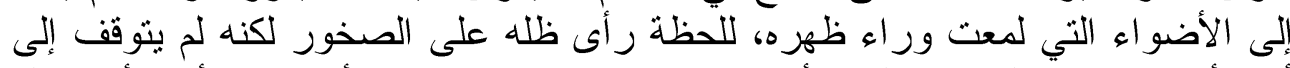

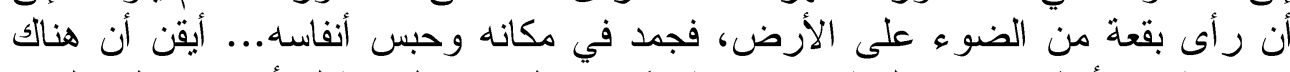

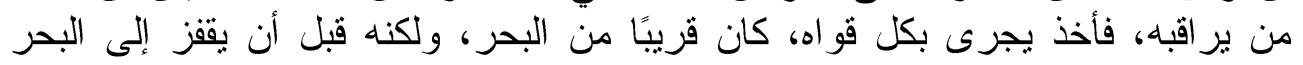

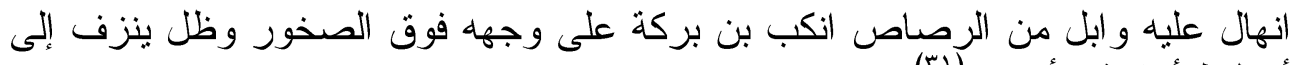

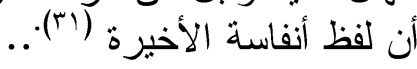




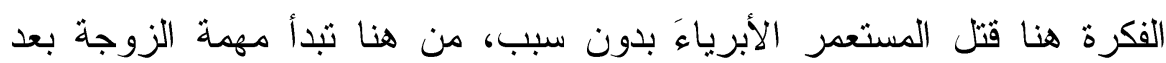

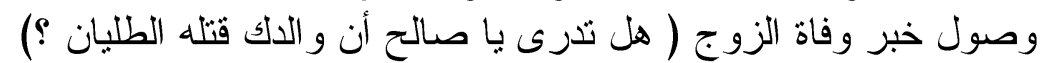

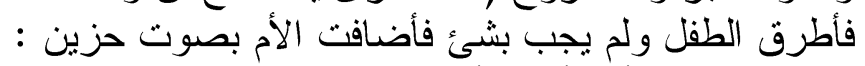

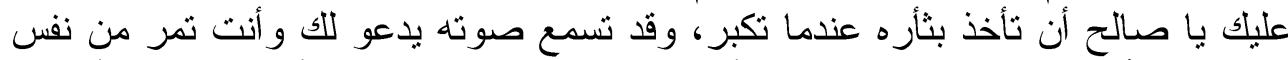

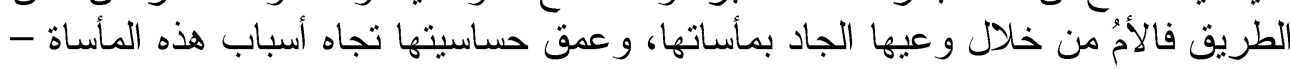

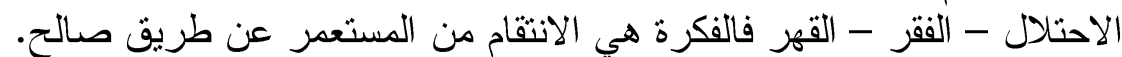

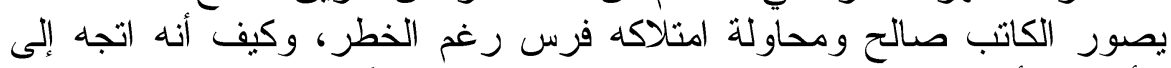

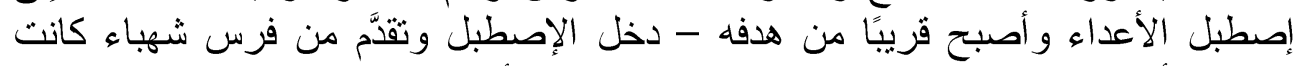

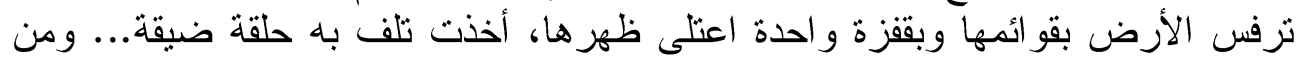

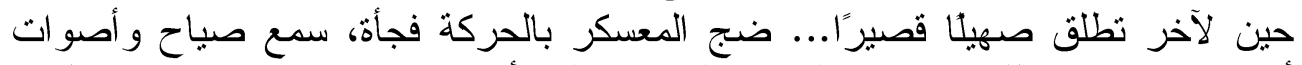

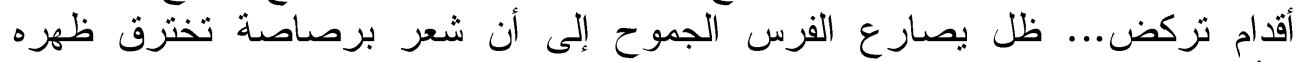
وبأخرى تنزلق على جبينه كالسكين، انحنى على عنق الفرس ثلى ثم همدت حركته.

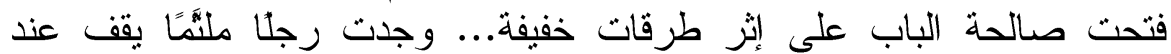

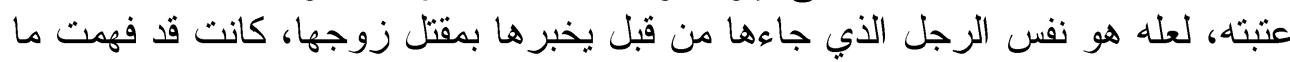

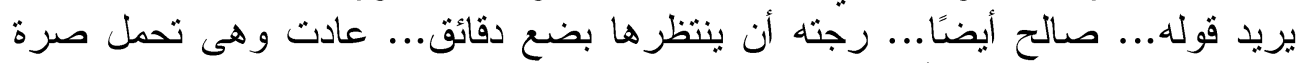
صغيرة في بدها.. سوف أذهب الهن معلك.

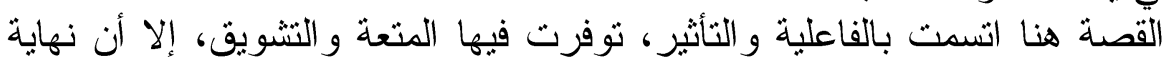
صالحة بقيت مفتوحة وللقارئ أن بتخيل النهاية.

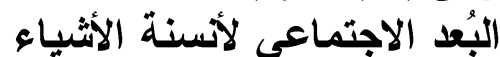

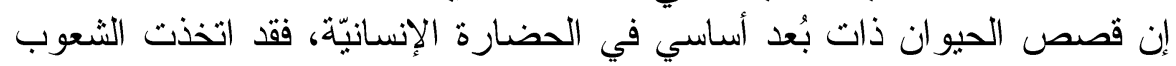

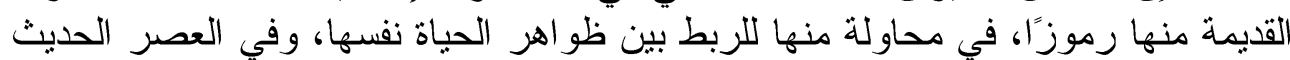

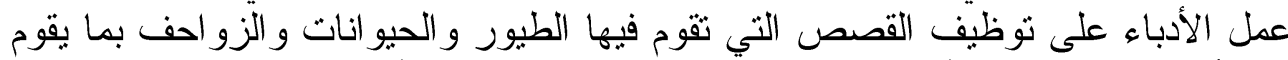

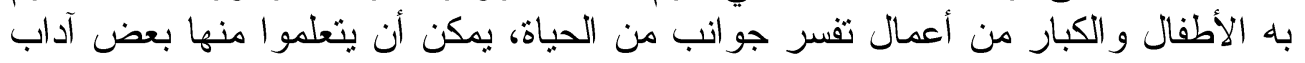

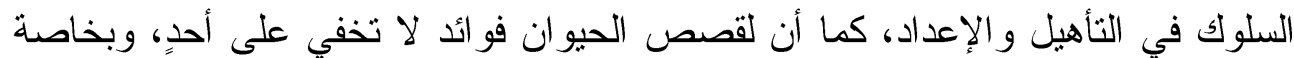

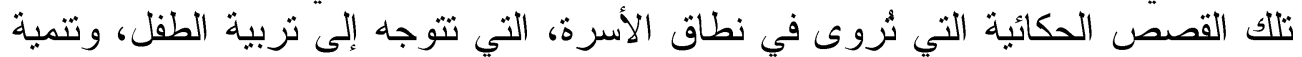

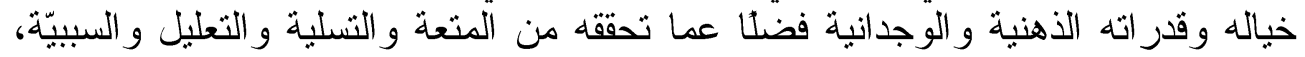

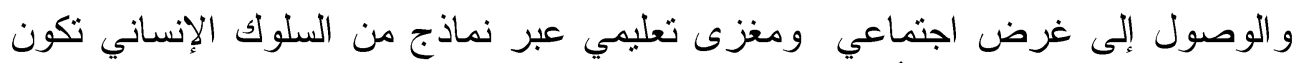
فيها شخصيات الحيوان أداة معرفية تشكل تصور اته عن الكون و الحياة والمحيط

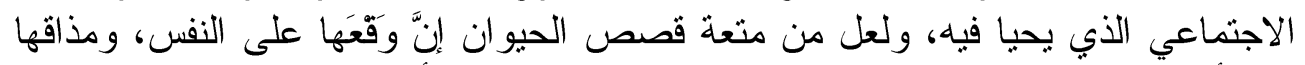

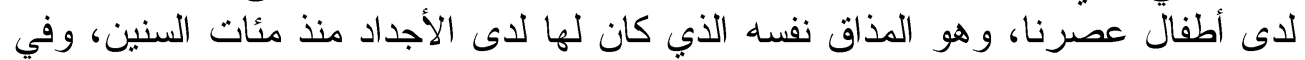

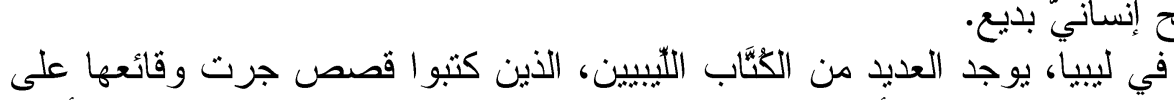

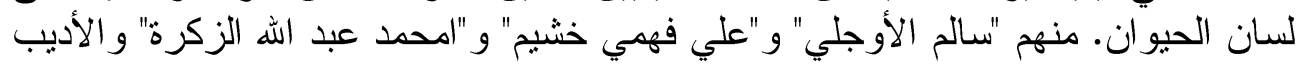

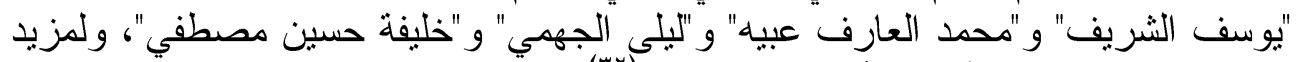

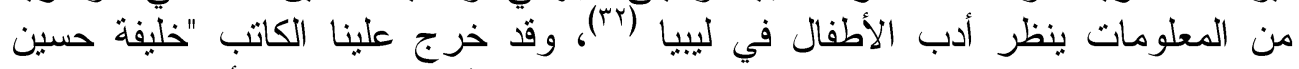

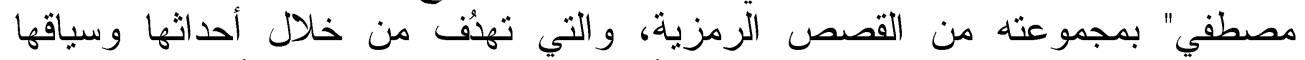

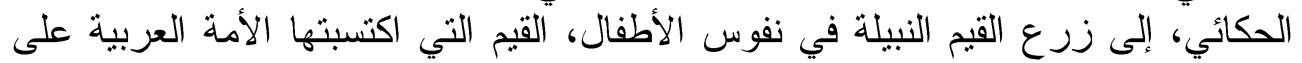

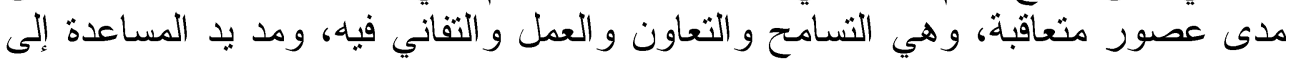


الآخرين، و التمسك بالصدق والأمانة، والاستعداد دومًا للتضحية من أجل المثل السامية

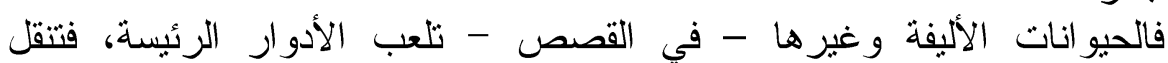

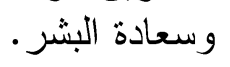

المعاني الخلقية و التربوية، بأسلوب جذاب قالف لا لا تمكن الثخصية الإنسانية من تأديتها.

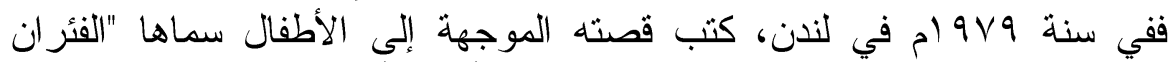

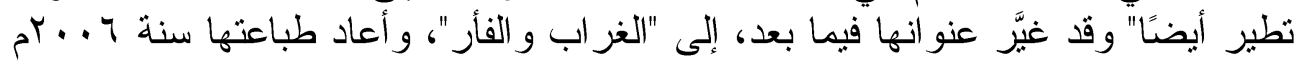

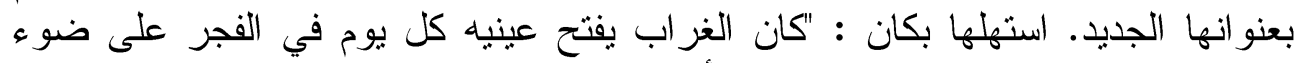

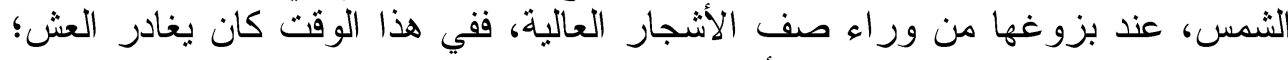

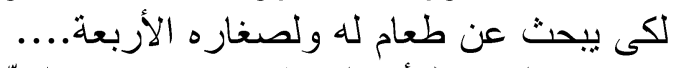

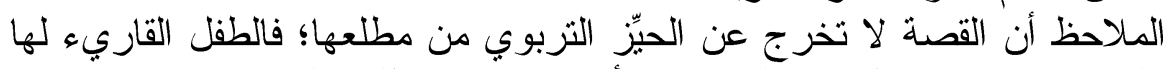

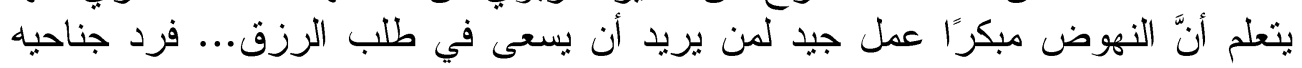
وطار محلقًا في الريح متجهُا إلى الحقول البعل البعيدة. ابتعد عن العش. وبينما كان بطير على العثى ارتفاع منخفض، رأى قطعة الجبن...

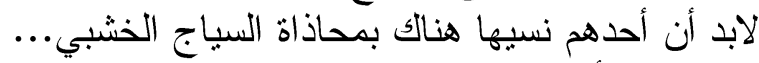

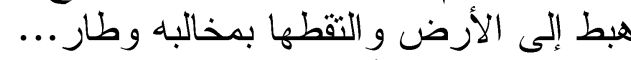

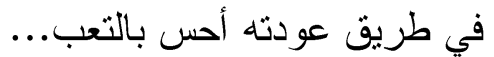

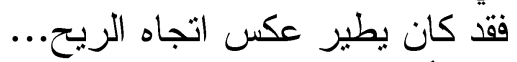

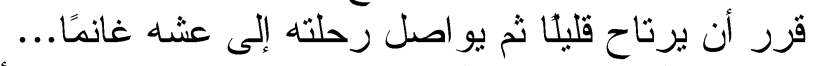

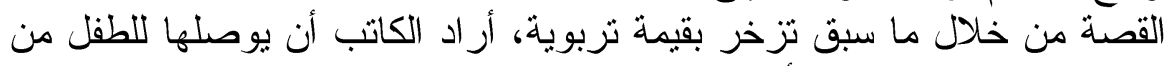

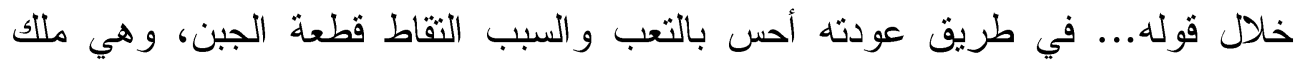

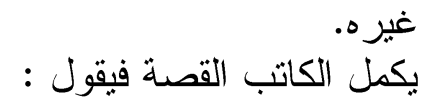

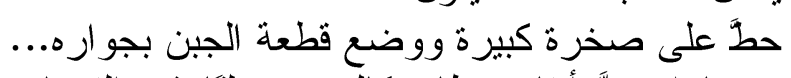

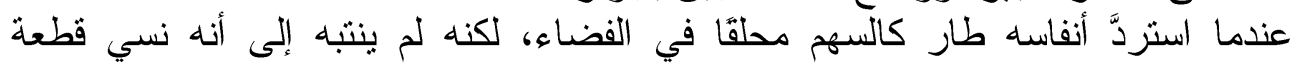
الجبن... المان أراد الكاتب من خلال الفقد أن يبين أن ما أخذناه بسهولة نفقده بسهولة...

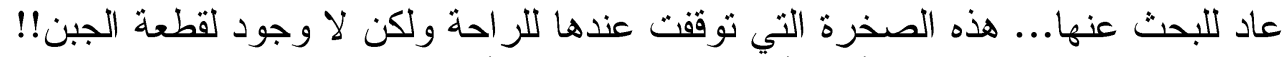

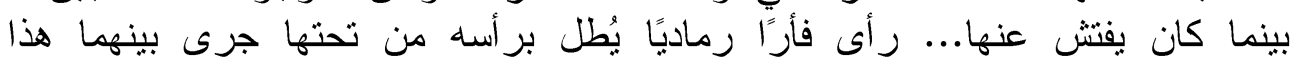
الحوار إنمان إننى أبحث عن قطعة جُبن كنت قد نسيتها فوق هذه الصخرة...

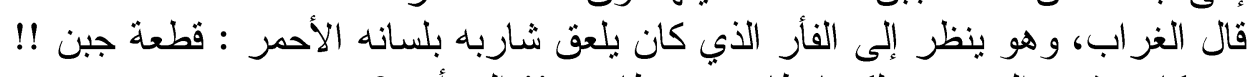

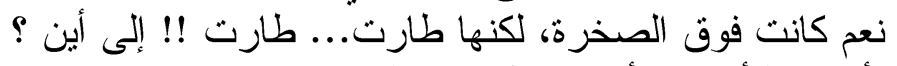

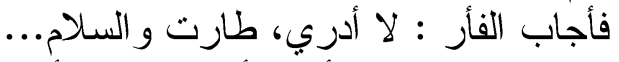

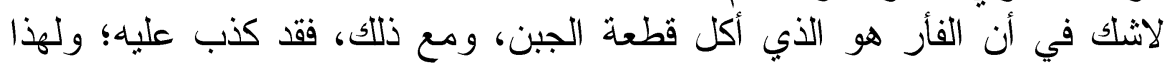

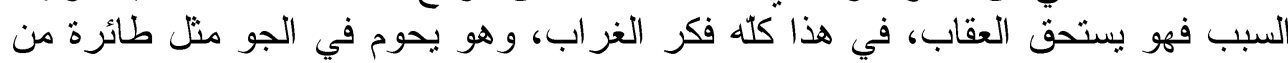
الورق.

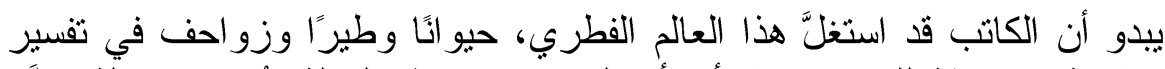

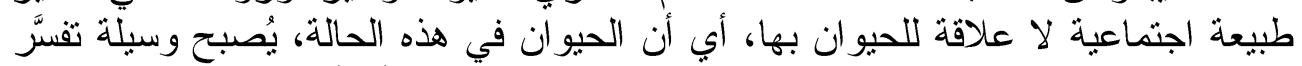

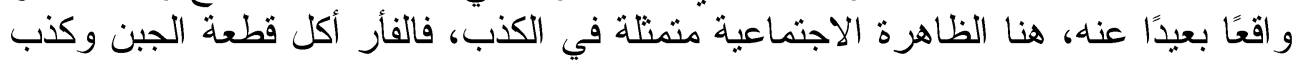


على الغراب عند قوله: نعم كانت فوق الصخرة لكنها طارت... إذن القصة جزء من وندئ تزبية الطفل و ثثقيفه وتعليمه.

بكمل الكاتب القصة قائثا : في اليوم التالي عاد الغراب وحط فوق الصخرة، وظل هادثًا في انتظار ظهور الفأر الكبير .

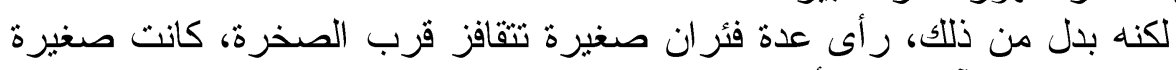

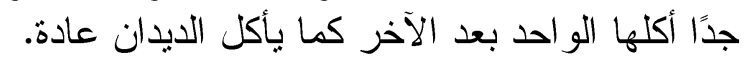

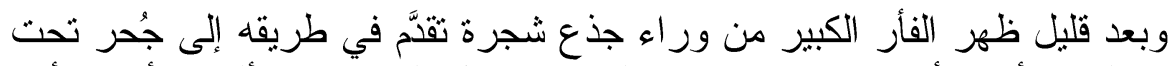

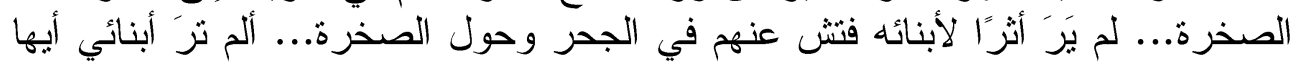
الغر اب... ؟

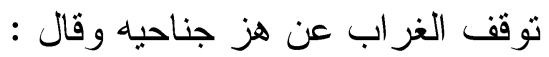

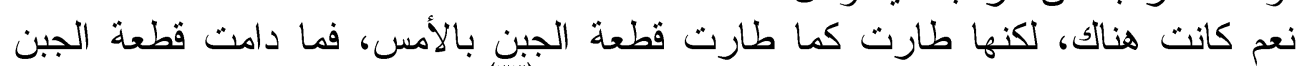

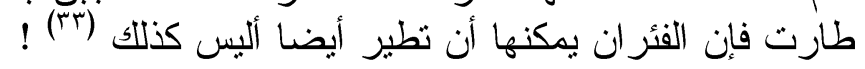

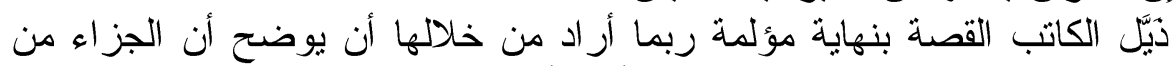

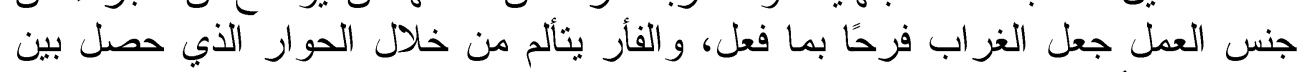
فالنهاية من شأنها أن تأخذ بمشاعر الطفل، الذي ما زال يحتفظ بأحاسيس الدهشة

$$
\text { الغر اب و الفأر . }
$$

$$
\text { و العفوية و التلقائية. }
$$

وما بستوجب الدهشة هو أكل الغراب للفئر ان الصغيرة. السؤال الذي يطرح نفسه

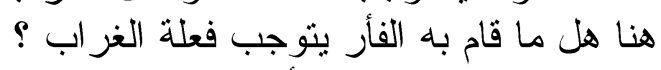

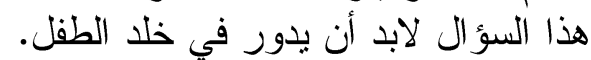

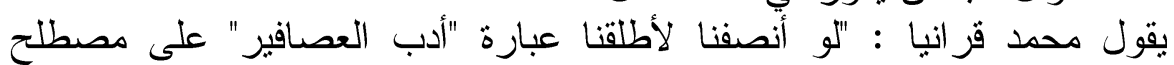

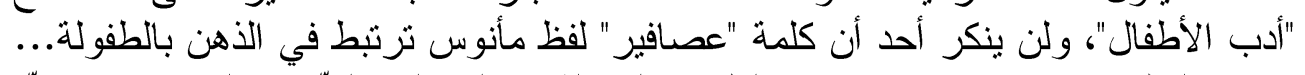

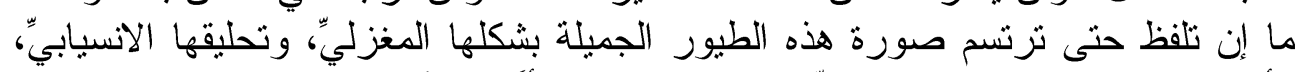

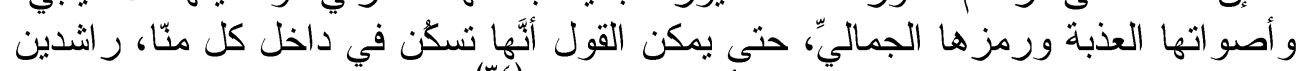

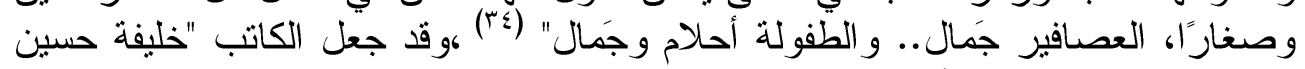

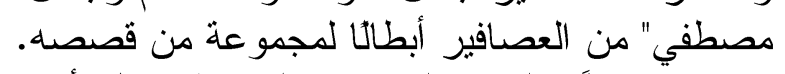

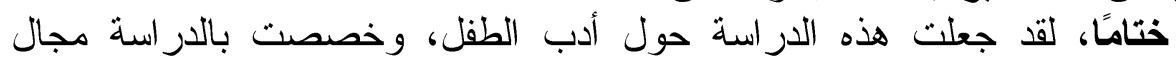

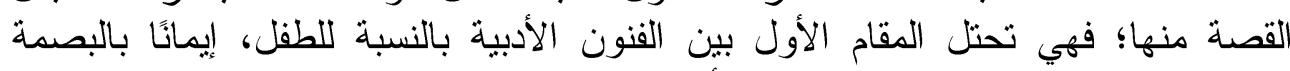

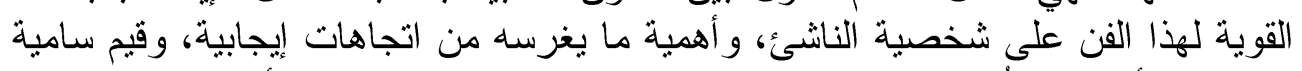

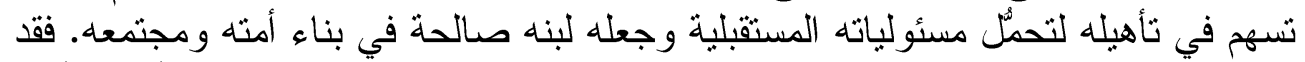

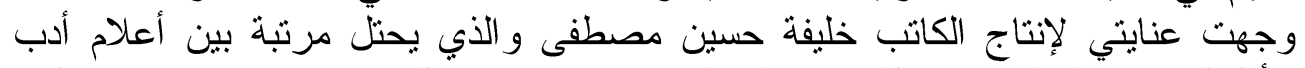

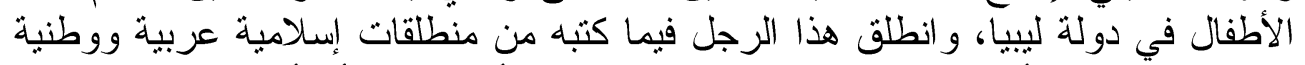

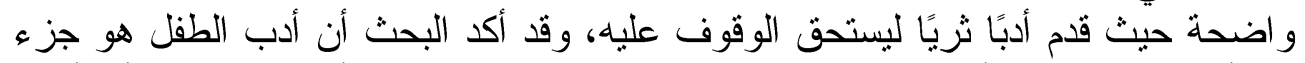

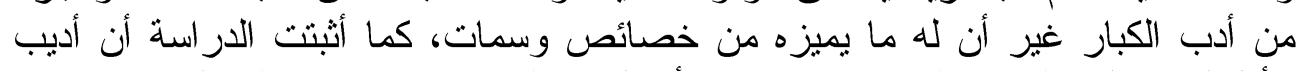

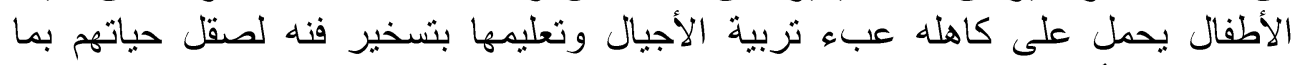

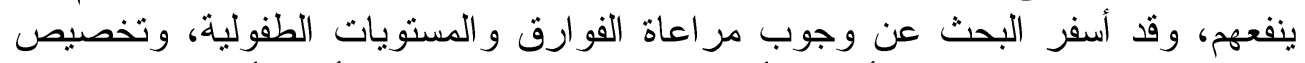

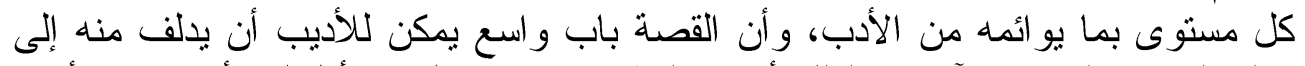

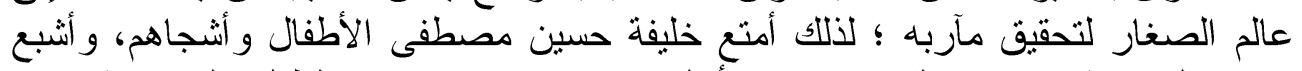

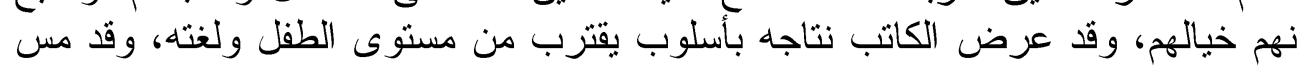


حسَّه المُرهف فتمرس في اختيار موضوعات تهدف للرقي بالطفل ، كما أكدت الدر اسة

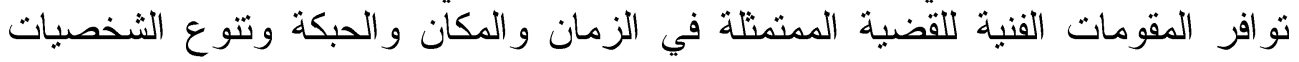
بين البشرية وغير البشرية. الاقتر احات والتوصيات:

و أتقدم بالاقتر احات التالية التي أرى فيها دعمًا لهذا الأدب الناشئ في ليبيا.

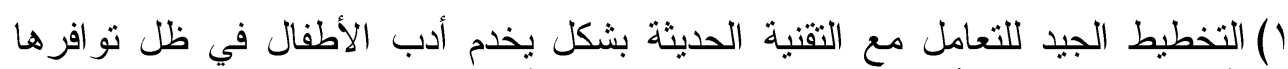
بأيدي كثيرة من الأطفال كالإنترنت مثنا لتقديم أعمال ترنقي بالطفة الطفل كعمل مكتبات

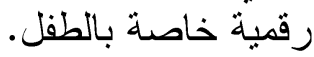
r) إعطاء مساحات أكبر في الأندية الثقافية لخدمة أدب الأطفال. r) تخصيص مكتبات للأطفال وتشجيع الأدباء البارزين على دعمهم بنتاجهم الموجه للطفل. §) الالتفات الجاد لموضوع الترجمة للغات الأجنبية، بما يخدم فكر الطفل العربي، و أطفال

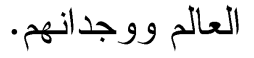

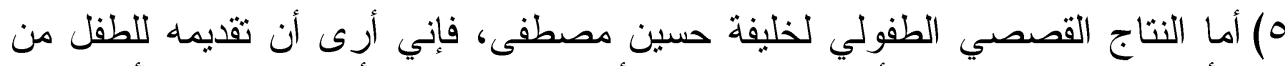

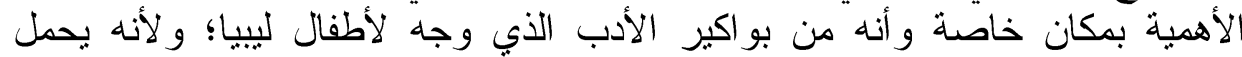

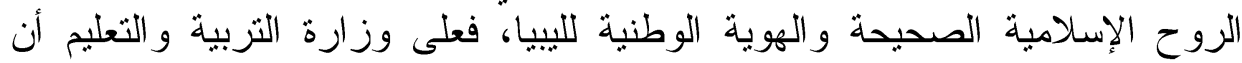
تعمل على توفير المكتبات المدرسية، ومعارض الكتب الوطنة الوطنية و الدولية. 


\begin{abstract}
Children 's Literature at the Khalifa Hussein Mustafa

To complement the requirements for obtaining a doctorate degree

By Hanan al-Saghir Abu al-Qasim

Children's literature is one of the forgotten corners of literary and critical studies, despite its importance. This may be due to the lack of interest of writers in this important aspect. Although the literature system of children in the Arab world is weak compared to international literature, it varies from environment to environment.

Research topic: The study dealt with the pioneering role of the Libyan writer Khalifa Hussein Mustafa in children's literature - a critical study in form and content.
\end{abstract}

\title{
Reasons for selection:
}

1. Develop a study that contributes to uncovering aspects of modern Libyan literary heritage.

2. The stories of the children at the successor of Hussein Mustafa did not receive serious study in depth specialized, was the research in his literary production in children's literature in order to put him in the right place among the other arts of his work.

Search Hypothesis: There are questions that can be raised about the subject of the study; and from these questions: To what extent succeeded Khalifa Mustafa Mustafa to produce a distinctive art in other children's literature in this area and whether to achieve in this form and content?

The research in production was for my stories by author Khalifa Mustafa Mustafa, who is one of the early beginnings of children's literature in Libya, while building our future generations correctly, building any civilized society that stems from the building of its generations. Therefore I present the following suggestions in which I see support for this emerging literature in Libya.

1 - good planning to deal with modern technology in a way that serves children's literature in the availability of many children, such as the Internet, for example to provide works that promote children as digital libraries for children.

2 - Try to overcome the difficulties facing the children's literature book in Libya financial expenses, especially to ensure the flow of this wonderful feat for our literature and the benefit of children from it.

3. Giving more space in cultural clubs to serve children's literature.

4 - the allocation of libraries for children and encourage prominent writers to support their child-oriented.

5 - Pay attention to the subject of translation of foreign languages, in order to serve the thought of the Arab child, children of the world and their senses. 
6. The childish storytelling of Khalifa Hussein Mustapha, I believe that his presentation of kindness is of particular importance since it is one of the earliest literature given to the children of Libya, because it bears the true Islamic spirit and the national identity of Libya and that the Ministry of Education provides it to school libraries, And international.

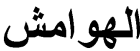

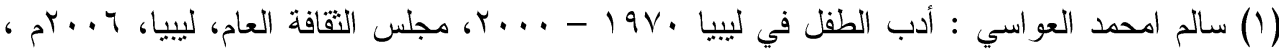

(†) سلوم درغام سلوم : توظيف القصة الطفولية السورية المعاصرة في التربية، سلسلة الدراسات (ب ())،

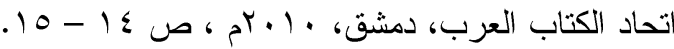

(T) عبد الحميد محمد عامر : أدب الأطفال في ليبيا - دراسة في مضمون القصة، سلسلة الدراسات (Y I)

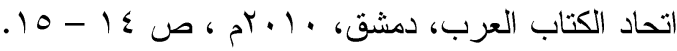

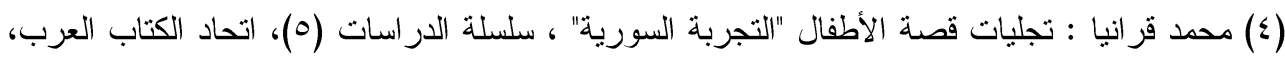

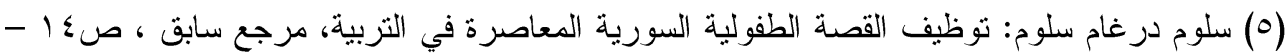

(") سلوم درغام سلوم : "توظيف القصة الطفولية السورية المعاصرة في التربية، مرجع سابق ، ص ؛

محسن ناصر الكناني : سحر القصة والحكاية، البحث عن النسغ الصاعد في نصوص مكانية

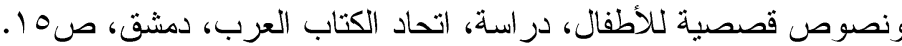

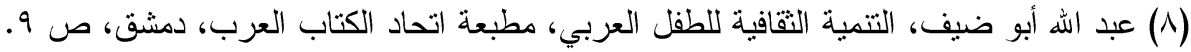

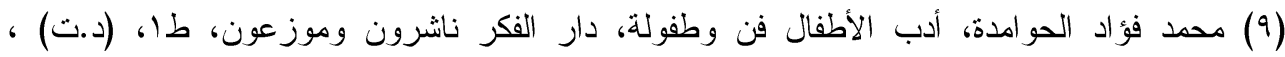

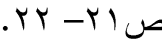

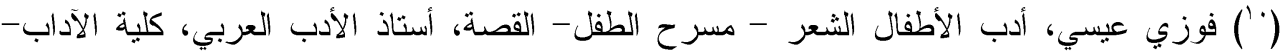

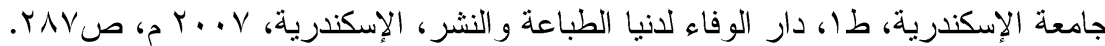
(1) كامل الكيلاني رائد أدب الأطفال في مصر لذه الهاهي العديد من القصص؛ أحمد سويلم، أطفالنا في عيون

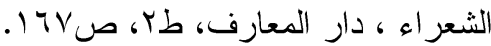

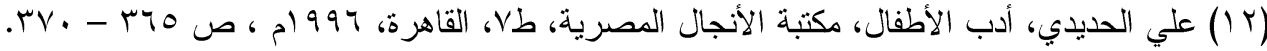

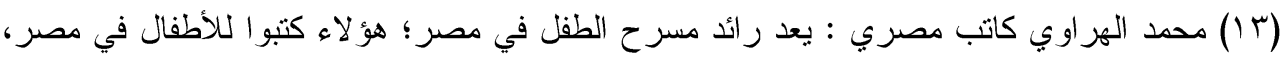
ص (ع () سليمان العيسى شاعر سوري له ديوان (غنو ا يا أطفال)؛ خليل أحمد خليل، موسوعة أعلام العرب

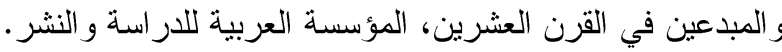

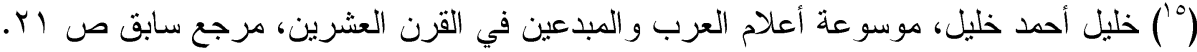

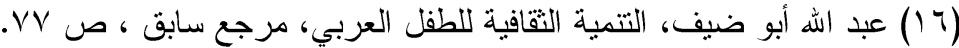


(lV) فريدة الأمين المصري : "أدب الأطفال في ليييا في النصف الثاني من القرن العشرين - دراسة

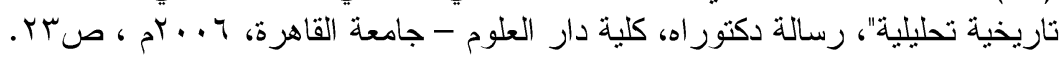

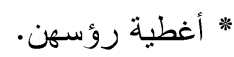

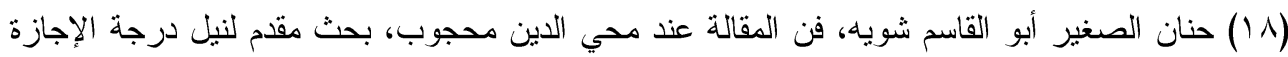

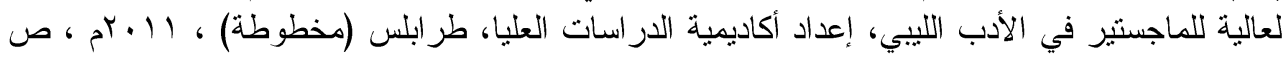

(9 (1) سعد أبو الرضا، النص الأدبي للأطفال أهدافه، ومصادره وسماته رؤية إسلامية، دار البشير طا

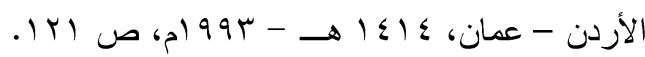

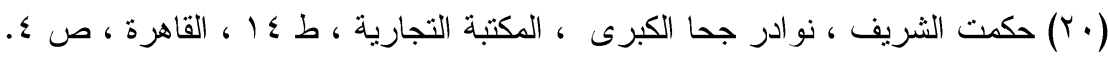

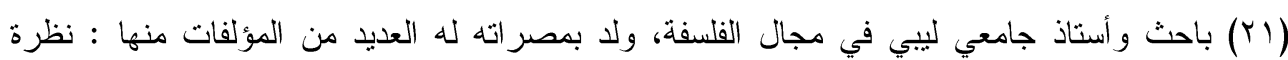

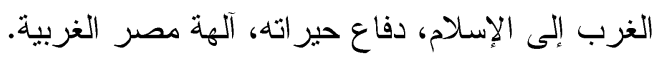

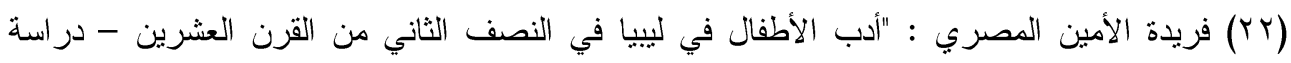

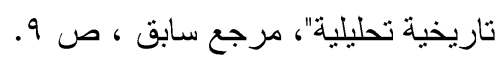

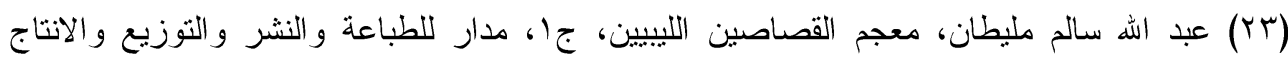

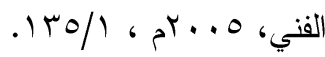

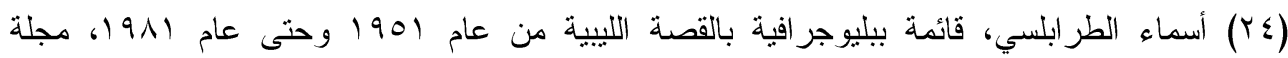

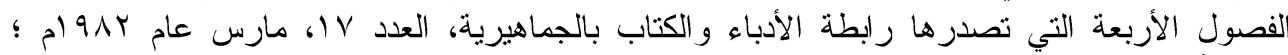

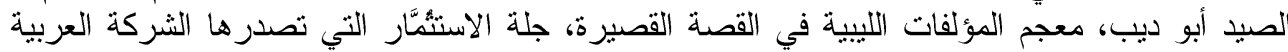

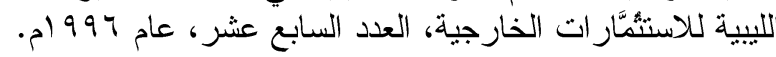

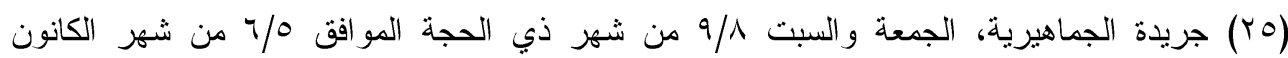
$.1 \mathrm{MVT}$ (Tr) كاتب ليبي معروف ولد في مزدة عام بـ9 1؛ عبد الله سالم مليطان، معجم القصاصين الليبيين، مرجع سابق، ص سأح.

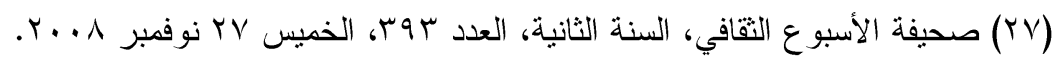

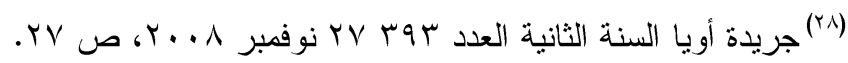

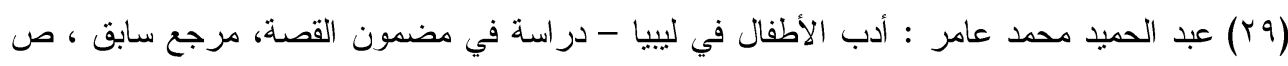
.194

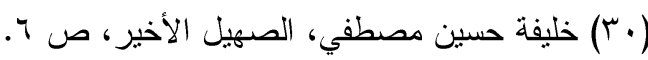

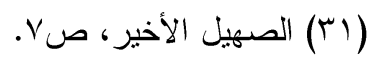

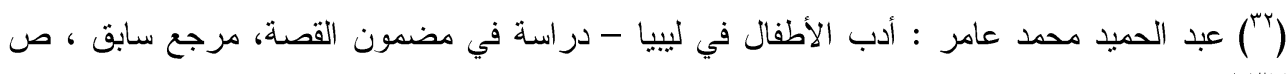

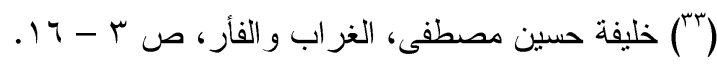

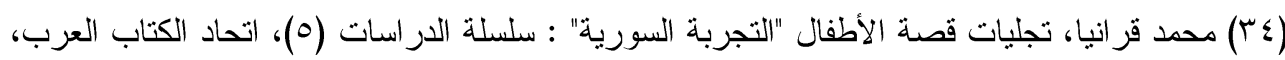




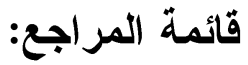

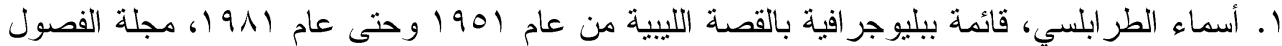

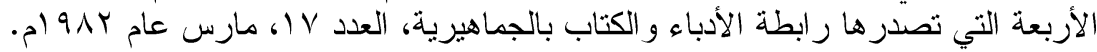

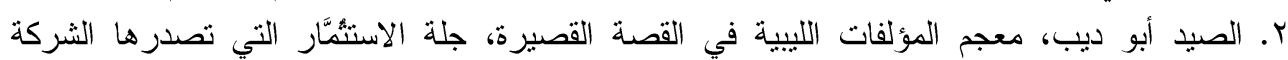

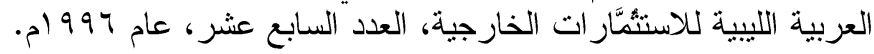

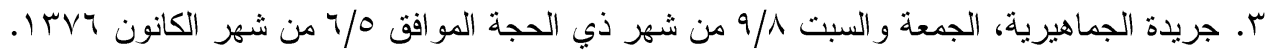

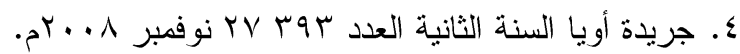

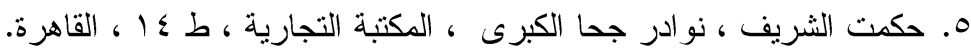

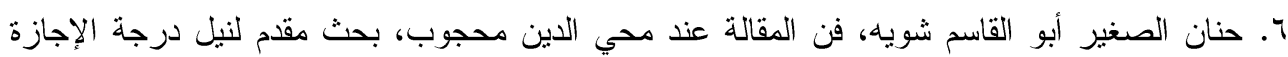

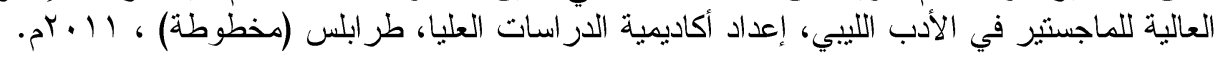
V V Vليفة حسين مصطفى، الغر اب و الفأر. ه. أليفة حسين مصطفي، الصهيل الأخير.

9. خليل أحمد خليل، موسوعة أعلام العرب و المبدعين في القرن العشرين، المؤسسة العربية للاراسة

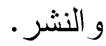

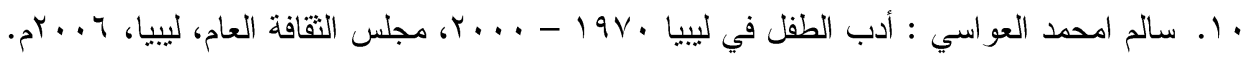

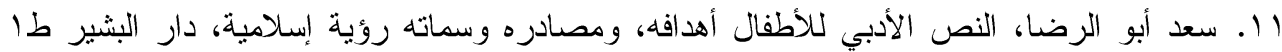

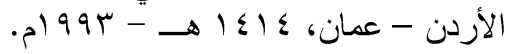

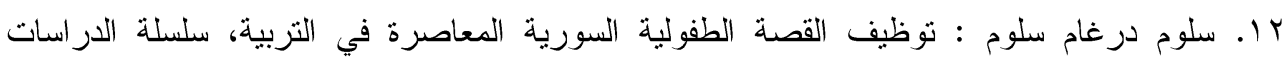

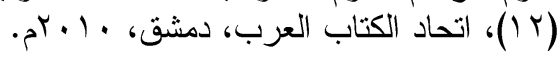

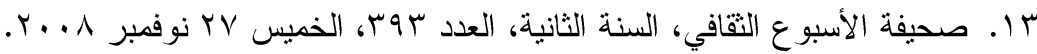

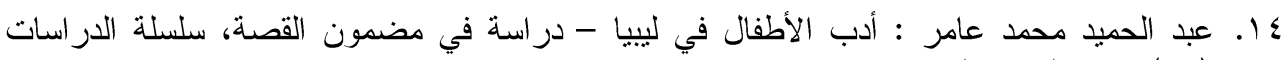

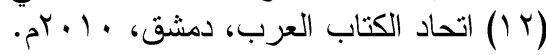

10. عبد الله أبو ضيف، التتمية الثقافية للطفل العربي، مطبعة اتحاد الكتاب العرب، دمشق.

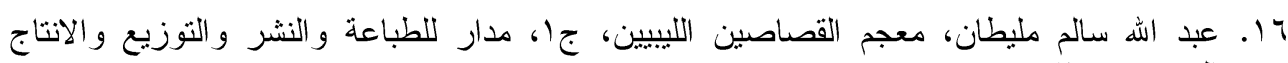

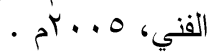

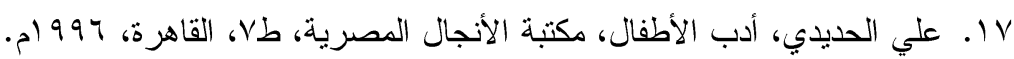

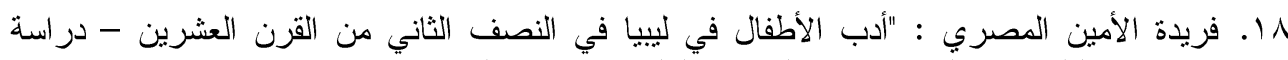

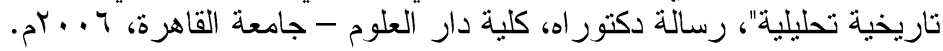

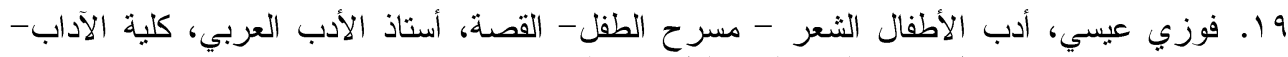

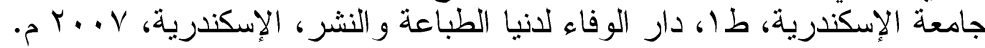

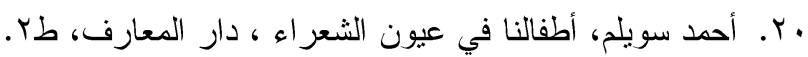

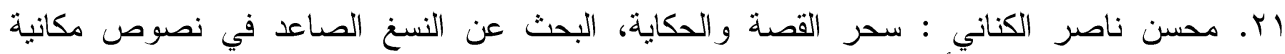

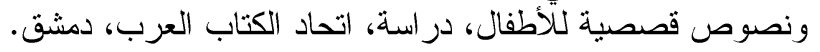

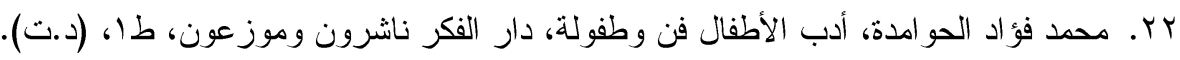

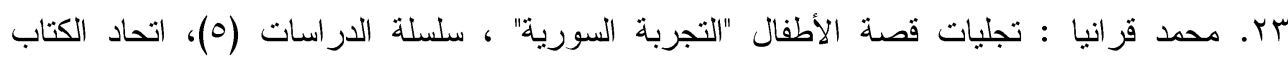

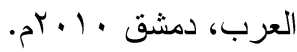

